\title{
A functional-group-based approach to modeling real-fuel combustion chemistry - II: Kinetic model construction and validation
}

\author{
Xiaoyuan Zhang*, S. Mani Sarathy* \\ Clean Combustion Research Center, King Abdullah University of Science and Technology, Thuwal, \\ 23955-6900, Saudi Arabia
}

\begin{abstract}
Construction of kinetic models to predict real-fuel combustion properties requires significant human and computational resources. In the first of this two-part study, a functional group correlation approach called FGMech was proposed for predicting the stoichiometric parameters in lumped pyrolysis reactions. The stoichiometric parameters were implemented in a recent real-fuel kinetic model, HyChem [Xu et al. Combust. Flame 193 (2018) 520-537], and the validity of this approach was demonstrated for simulating real-fuel combustion. The present work extends the FGMech approach for developing surrogate and real-fuel kinetic models. Our approach is fundamentally different from the HyChem development approach in that no parameters are tuned to match actual real-fuel pyrolysis/oxidation data, and all model parameters are derived only from functional group data. Along with the stoichiometric parameters obtained in the first part of this study, the thermodynamic data, lumped reaction rate parameters and transport data were predicted in this work based on the functional group characterization of real fuels. The Benson group additivity method was adopted to estimate the thermodynamic data of real fuels, while rate rules developed for pure fuels were used to estimate the rate constants of lumped reactions in real-fuel models. For transport data, normal boiling point, critical temperature and pressure (estimated using the Joback group contribution method) were used to obtain Lennard-Jones parameters. The format of lumped reactions in FGMech followed the HyChem approach, and the base mechanism was adopted from the AramcoMech 2.0 and
\end{abstract}

\footnotetext{
* Corresponding author. E-mail: xiaoyuan.zhang@kaust.edu.sa.

*Corresponding author. E-mail: mani.sarathy@kaust.edu.sa.
} 
USC Mech II, respectively, to compare the model performance with different base mechanisms. Fourteen surrogate and twelve real fuel models were developed based on this approach; they were validated against the experimental data in the literature. FGMech's performance was also compared with detailed and reduced models available in the literature. FGMech reasonably captures the experimental data in the literature, indicating that the present modeling approach is promising for modeling the combustion behavior of fuel, including surrogate mixtures and real fuels.

Keywords: surrogate fuels; real fuels; kinetic model; functional groups; FGMech

\section{Introduction}

Global applications for petroleum-derived transportation fuels are growing unsustainably [1]; improving fuel efficiency and reducing emissions with advanced fuel/engine designs [2-4] are highly effective mitigators. Given the cost and limitations of traditional empirical-based designs, computer assisted engineering is essential for advancing fuel/engine designs. In this context, chemical kinetic models for real-fuel combustion can assist in understanding fuel/engine interactions $[5,6]$ by predicting chemical heat release, critical radicals and intermediates that lead to ignition and the formation of stable pollutant species.

The literature proposes many surrogate fuel formulation approaches for mimicking real-fuel combustion [7-12]. In many of these, a limited number of fuel components with well-defined structures and compositions are selected to represent the hydrocarbon classes present in real fuels $[13,14]$; in this way, these multi-component surrogates can greatly reduce the compositional complexity of real fuels and still reproduce their combustion behavior. However, detailed models for multi-component surrogate fuels are generally not compact enough for computational fluid dynamic (CFD) engine simulations. While mechanism reduction tools are available, their application has been somewhat limited to binary and ternary surrogate mixtures, which have limited ability to capture many complex 
combustion kinetic phenomenon [11,12].

An alternative approach for reducing the size of kinetic models for large and complicated feeds is to use lumping strategies. Ranzi and his coworkers have made pioneering contributions in this area $[15,16]$. In their lumping strategies, the apparent stoichiometry of large intermediate radicals can be deduced based on their decomposition pathways and steady-state approximations [17]. Both horizontal lumping of isomeric species and vertical lumping of homologous intermediate species for a hydrocarbon family (i.e., $n$-alkanes) have been implemented to reduce the number of species in a kinetic model. These lumping strategies combined with kinetic parameters have been incorporated into an automatic generation program of reaction mechanism, called MAMOX++ [18]. Jaffe and Quann $[19,20]$ proposed the structure-oriented lumping (SOL) approach to describe the composition, reactions, and properties of complex hydrocarbon mixtures. Based on this approach, a mixture is represented as a set of vectors, in which each entry corresponds to the amount of a specific functional group existing in the molecule. It assumes that functional groups are chemically independent in a molecule, disregarding the connectivity between them. Unlike SOL, which assumes few interactions between functional groups, Mehl et al. [21] proposed a functional group approach in which the fuel surrogate was defined in terms of pseudospecies containing the functional groups in the actual fuel. These pseudocomponents, representing linear, branched, aromatic, saturated, and unsaturated structures, can undergo typical reactions responsible for low-temperature ignition of hydrocarbons, as well as interactions occurring in fuel blends. Advancing on this idea, a fragment-based approach was recently developed to further reduce the scalability [22]. In contrast to the pseudocomponents, fragments may consist of multiple functional groups, as needed, to preserve their original connectivity.

Unlike the aforementioned lumping methods, which consider the detailed reaction network, a recent physics-based approach (HyChem [23]), was proposed to model real-fuel combustion while 
ignoring the complex reaction processes. Seven lumped reactions, directly connecting the fuel molecule and its decomposition products, were used to describe the high-temperature oxidation of real fuels. The stoichiometric parameters and the kinetic rate parameters of these lumped reactions were obtained by fitting the speciation data measured in shock tubes and flow reactors [24]. However, even (oxidative) pyrolysis speciation data may not be sufficient to fit all the rate constants in such a realfuel model, for example, $\mathrm{H}$-atom abstraction reactions from the fuel by $\mathrm{HO}_{2}$ and $\mathrm{O}$ are not sensitive to (oxidative) pyrolysis experimental data, so their rate parameters cannot be fitted. Therefore, it was also necessary for the authors [24] to use ignition delay time data to fit rate constants for H-atom abstraction reactions by $\mathrm{HO}_{2}$ radicals. We believe that this reliance on empirical real-fuel combustion measurements can be replaced by a theoretical approach for estimating stoichiometric and reaction rate parameters based on real-fuel functional-group data.

In the companion paper to this work [25], it was shown that the stoichiometric parameters of lumped pyrolysis reactions for surrogate mixtures and real fuels could be obtained from functional group correlations (FGMech). These correlations for FGMech were trained on a database of pure component pyrolysis speciation and stoichiometries of lumped pyrolysis steps from a 50-component lumped mechanism [26], and then tested on surrogate mixtures and real fuels. This FGMech approach lays the foundation for developing kinetic models for real fuels. In this work, the functional group approach is expanded by obtaining the thermodynamic, kinetic and transport data, so that FGMech can be developed for real fuels without relying on fitting against real-fuel experimental data. Fourteen surrogate and twelve real-fuel models were constructed based on the present FGMech philosophy, and then were validated against the experimental data available for surrogate and real fuels. Finally, the relationships between the functional groups and predicted intermediate distributions are discussed. 


\section{Model construction}

The basic structure of FGMech follows the HyChem approach [24], while the model parameters are different. The kinetic model development hierarchy is presented in Fig. 1. The model consists of a lumped reaction mechanism and a base mechanism. The base mechanism describes the pyrolysis and oxidation of small hydrocarbon and oxygenated hydrocarbon intermediates, while the lumped mechanism connects the fuel mixture with its decomposition products. The present FGMech base mechanism was adopted from the detailed high-temperature mechanism of AramcoMech 2.0 [27] and the USC Mech II [28], respectively, to compare the influence of different base mechanisms on model performance. The lumped reaction mechanism for fuel pyrolysis was developed based on characterization of the fuel's functional group. The stoichiometric parameters of lumped pyrolysis reactions were calculated based on correlations using multiple linear regression (MLR), as described in the companion paper [25]. The MLR model develops a relationship between a fuel's functional groups and its stoichiometric parameters; the MLR was trained on pure component pyrolysis data and stoichiometries of lumped reactions from a lumped mechanism for various fuels, and then tested on real fuel mixture pyrolysis data [25]. Thermodynamic data and the kinetic rate parameters in FGMech were estimated using the Benson group additivity (GA) method and rate rules developed for various pure fuels, respectively. Transport data is required for simulating combustion in transport-controlled regimes (e.g., laminar flames). The functional group-based Joback method [29] was followed to estimate the normal boiling point, critical temperature and pressure, which were then used to calculate the Lennard-Jones parameters. We introduced the details of obtaining stoichiometric parameters in the companion paper to this work [25]; therefore this section focuses on the estimation approach for rate constants of lumped reactions, thermodynamic and transport data of fuel molecules in FGMech's lumped reaction mechanism. The functional group distributions in real fuels were obtained from 
structural characterization measurements in literature [14,30-33] using comprehensive detailed hydrocarbon analysis (DHA) [34-37], or other quantitative analytic techniques [14,30-32]. Such methods, based on gas chromatography, mass spectrometry, and/or nuclear magnetic resonance spectroscopy - to name a few - are routinely employed fuel characterization techniques. In this way, the constituent components in a real fuel were identified and quantified, and they were used to calculate the number (i.e., counts) and mass fraction of functional groups present in a real fuel.

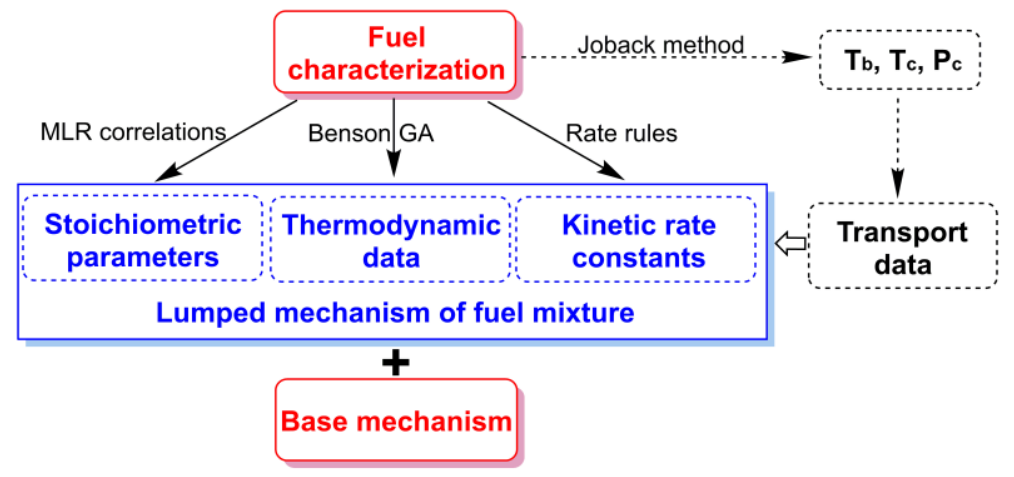

Fig. 1. FGMech development hierarchy for modeling fuel mixtures using a functional group approach (see text for details).

\subsection{Rate constants of lumped reactions}

Following the HyChem approach [23,24], seven lumped reactions were used to construct the sub-mechanism for fuel mixtures, i.e. R1-R7, where $\mathrm{C}_{\mathrm{m}} \mathrm{H}_{\mathrm{n}}$ represents the fuel molecule and $\alpha, \beta, \lambda_{3}$, $\lambda_{4}$ and $\chi$ are stoichiometric parameters. Other parameters, i.e. $\mathrm{e}_{\mathrm{d}}, \mathrm{b}_{\mathrm{d}}, \mathrm{e}_{\mathrm{a}}$ and $\mathrm{b}_{\mathrm{a}}$, can be calculated from the balances of the $\mathrm{C}$ and $\mathrm{H}$ elements. Details can be found in $\mathrm{Xu}$ et al. [24].

$$
\begin{array}{lr}
C_{m} H_{n} \rightarrow e_{d}\left(C_{2} H_{4}+\lambda_{3} C_{3} H_{6}+\lambda_{4} C_{4} H_{8}\right)+b_{d}\left[\chi C_{6} H_{6}+(1-\chi) C_{7} H_{8}\right]+\alpha H+(2-\alpha) C_{3} & \mathrm{R} 1 \\
C_{m} H_{n}+H \rightarrow H_{2}+\sum_{p} & \mathrm{R} 2 \\
C_{m} H_{n}+\mathrm{CH}_{3} \rightarrow \mathrm{CH}_{4}+\sum_{p} & \mathrm{R} 3 \\
C_{m} H_{n}+\mathrm{OH} \rightarrow \mathrm{H}_{2} \mathrm{O}+\sum_{p} & \mathrm{R} 4 \\
C_{m} H_{n}+\mathrm{O}_{2} \rightarrow \mathrm{HO}_{2}+\sum_{p} & \mathrm{R} 5 \\
C_{m} H_{n}+\mathrm{HO}_{2} \rightarrow \mathrm{H}_{2} \mathrm{O}_{2}+\sum_{p} & \mathrm{R} 6
\end{array}
$$


$\mathrm{C}_{m} \mathrm{H}_{n}+\mathrm{O} \rightarrow \mathrm{OH}+\sum_{p}$

where

$\sum_{p}=\gamma C H_{4}+e_{a}\left(C_{2} H_{4}+\lambda_{3} C_{3} H_{6}+\lambda_{4} C_{4} H_{8}\right)+b_{a}\left[\chi C_{6} H_{6}+(1-\chi) C_{7} H_{8}\right]+\beta H+(1-\beta) C H_{3}$

$\mathrm{R} 1$ is the unimolecular decomposition reaction among the seven lumped reactions; in real fuels, we cannot precisely determine how the functional groups are connected to each other, so we adopted several surrogate components to represent the real fuels. The surrogate formulation was based on matching the functional groups of the real fuels. The final rate constant of $\mathrm{R} 1$ was the sum of the rate constants of each $\mathrm{C}-\mathrm{C}$ bond dissociation reaction, except those of aromatic $\mathrm{C}-\mathrm{C}$ bonds. $\mathrm{R} 2-\mathrm{R} 7$ lump the $\mathrm{H}$-atom abstraction reactions and the subsequent isomerization and $\beta$-scission reactions of fuel radicals. Based on previous studies on the time-scale analysis [38], H-atom abstraction reaction is the rate-limiting step among the three reaction processes. Therefore, the rate constant of each $\mathrm{H}$-atom abstraction reaction was assigned as the rate constant of the respective overall lumped reaction. Since the identity and quantity of the functional groups in real fuels can be obtained from structural characterization experiments [30], the rate constants of the H-atom abstraction reactions occurring on each individual functional group were added together (neglecting the aromatic $\mathrm{CH}$ group) based on Eq. 1, where $k_{i}$ represents the rate constant of an individual functional group (e.g. paraffinic $\mathrm{CH}_{3}$ ), while $X_{i}$ is the count of this functional group, and the total rate constant $(k(T))$ was considered to be the final rate constant of each lumped reaction.

$$
k(T)=\sum_{i} k_{i, T}\left(X_{i}\right)
$$

In this work, rate rules, developed for pure fuels, were adopted for the rate constants of individual $\mathrm{C}-\mathrm{C}$ bond dissociation and $\mathrm{H}$-atom abstraction reactions. This type of rate rules approach has been adopted by several research groups [18,39-42] to facilitate the development of chemical kinetic models for single component fuels. Here, we follow a similar methodology and apply it to fuel mixtures based 
on their constituent functional groups. For unimolecular decomposition reactions, rate constants of the bond dissociation reactions for paraffinic $\mathrm{C}-\mathrm{C}$ bonds like $\mathrm{CH}_{3}-\mathrm{CH}_{2}, \mathrm{CH}_{2}-\mathrm{CH}_{2}, \mathrm{CH}_{3}-\mathrm{CH}$ and $\mathrm{CH}_{2}-\mathrm{CH}$ etc. were adopted from previous models for $n$-alkanes [39,43] and iso-alkanes [40,41]. Rate constants of the bond dissociation reactions for naphthenic $\mathrm{CH}_{2}-\mathrm{CH}_{2}$, naphthenic $\mathrm{CH}$-paraffinic $\mathrm{CH}_{2}$ and naphthenic $\mathrm{CH}$-paraffinic $\mathrm{CH}_{3}$ were adopted from previous models for cycloalkanes [44-46]. Rate constants of the bond dissociation reactions of benzyl $\mathrm{CH}_{2}$ and $\mathrm{H}$ (i.e. the unimolecular decomposition reaction of toluene), benzyl $\mathrm{CH}_{2}$-paraffinic $\mathrm{CH}_{2}$, benzyl $\mathrm{CH}_{2}$-paraffinic $\mathrm{CH}_{3}$ were adopted from previous models for alkylated benzenes [47-49]. For the $\mathrm{H}$-atom abstraction reactions occurring on benzylic $\mathrm{CH}_{3}$ and $\mathrm{CH}_{2}$ groups, the rate constants from previous models of toluene [47] and ethylbenzene [48], respectively, were used. Rate constants of the H-atom abstraction reactions on naphthenic $\mathrm{CH}_{2}$ and $\mathrm{CH}$ groups were adopted from previous cycloalkane models [44-46], while those on paraffinic $\mathrm{CH}, \mathrm{CH}_{2}$ and $\mathrm{CH}_{3}$ groups were taken from previous alkane models [39-41,43]. The rate rules for each of C-C bond dissociation and $\mathrm{H}$-atom abstraction reactions are listed in Tables S1-S7 in the Supplementary Material.

The present estimated rate constants of R2-R7 for the Jet POSF 10325 model are compared with those from the HyChem model [24], which were obtained by fitting the experimental data. The most important reactions among them are the $\mathrm{H}$-atom abstraction reactions of fuel by $\mathrm{H}, \mathrm{OH}$ and $\mathrm{HO}_{2}$ radical. As seen from Fig. 2a, the fitted rate constant of $\mathrm{R} 4$ (H-atom abstraction reaction by $\mathrm{OH}$ radical) from [24] is one order of magnitude slower than the estimated value in this work over 800-2000 K, while the fitted rate constant of $\mathrm{R} 6$ ( $\mathrm{H}$-atom abstraction reaction by $\mathrm{HO}_{2}$ radical) from [24] is three to eight times faster than the present estimated result. The temperature dependency of R4 is very weak in the rates from [24], while there is slight increase in R4 at higher temperatures in this work. Above 1700 $\mathrm{K}$, the $\mathrm{k}_{6}$ is higher than $\mathrm{k}_{4}$ in [24], which is unusual, as abstractions by $\mathrm{OH}$ radicals are typically faster 
than those by $\mathrm{HO}_{2}$ radical [40,41]. In FGMech, $\mathrm{k}_{6}$ is always much slower than $\mathrm{k}_{4}$. In general, according to the rate rules developed for pure fuels, the present estimated $\mathrm{k}_{4}$ and $\mathrm{k}_{6}$ appear to be more reasonable $[39,43]$. For $\mathrm{R} 2$ (H-atom abstraction reaction by $\mathrm{H}$ atom), the estimated rate constant in this work is close to that obtained from the HyChem model [24]. Comparisons for the less important reactions, i.e. R3, R5 and R7, are found in Fig. 2b. The estimated rate constants of R3 and R7 are close to those from [24], while $\mathrm{k}_{5}$ is around two orders of magnitude lower than $\mathrm{k}_{5}$ from [24]. In summary, the large differences in some rate constants between the FGMech and HyChem approaches, such as $\mathrm{k}_{4}, \mathrm{k}_{5}$ and $\mathrm{k}_{6}$, originate from different model construction principles. In the HyChem approach, kinetic parameters were obtained by fitting the experimental data while neglecting the kinetic rules of these reactions. In contrast, our FGMech approach obeys rigid rate rules developed for pure fuels with full consideration of the nature of these reactions.

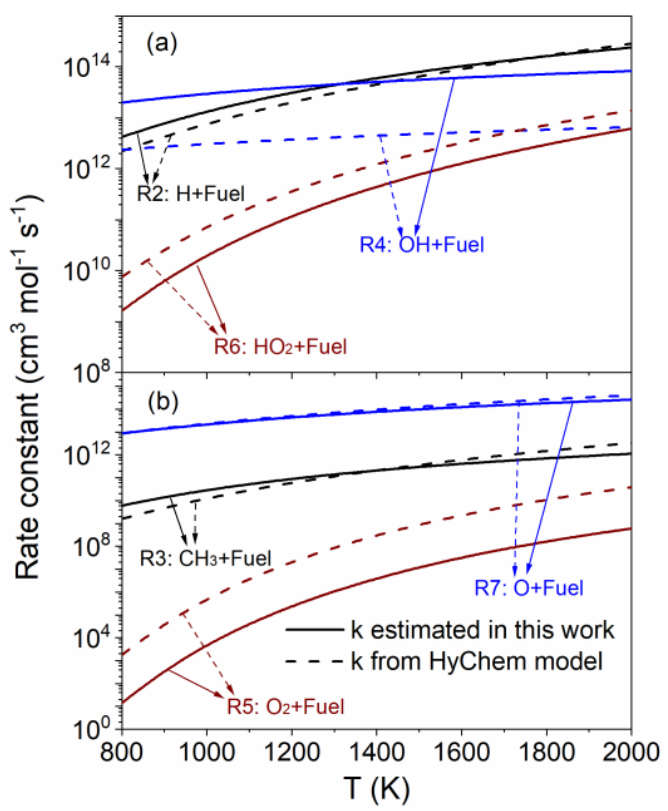

Fig. 2. Comparison of rate constants of R2-R7 in Jet POSF 10325 model. Solid and dashed lines represent rate constants from the present work (FGMech) and HyChem model [24], respectively.

Following the present functional group-based approach, the rate constants of R1-R7 for various 
surrogate mixtures and real fuels were estimated. Figure $3 \mathrm{a}$ presents a comparison of the estimated $\mathrm{k}_{2}$, $\mathrm{k}_{4}$ and $\mathrm{k}_{6}$ for five jet fuel surrogate mixtures and a real jet fuel POSF 10264 . The $\mathrm{k}_{2}, \mathrm{k}_{4}$ and $\mathrm{k}_{6}$ differences between various fuels are within 50\%, which implies the kinetic similarities between the jet fuel surrogates and real jet fuel. Figure $3 \mathrm{~b}$ compares the estimated rate constants of R2, R4 and R6 for four jet fuels and one rocket propellant. POSF 10264, POSF 10325, POSF 10289, and POSF 4658 are jet fuels that mainly consist of $n$-paraffins, iso-paraffins, cyclo-paraffins and aromatics. RP POSF 5433 is a rocket propellant mainly consisting of $n$-paraffins, iso-paraffins and cyclo-paraffins. The average molecular formula and $\mathrm{H} / \mathrm{C}$ ratios of the five real fuels are close. As shown in Fig. 3b, for $\mathrm{k}_{2}$, $\mathrm{k}_{4}$ and $\mathrm{k}_{6}$, the differences between the various jet fuels are within $20 \%$, consistent with those from [24], in which the rate constants of R1-R7 for different jet fuels are the same, based on fitting the experimental data. However, $\mathrm{k}_{2}, \mathrm{k}_{4}$ and $\mathrm{k}_{6}$ for the jet fuels are as much as $70 \%$ lower than those of the rocket fuel, as shown in Fig. 3b, which implies greater kinetic differences between jet and rocket fuels. In the companion paper [25] to this work, it was found that the stoichiometric parameters for various jet fuel surrogates and real jet fuels were similar, while they were different from other real fuels such as RP POSF 5433. In this work, similarities and differences in kinetic parameters are also observed among these fuels. 


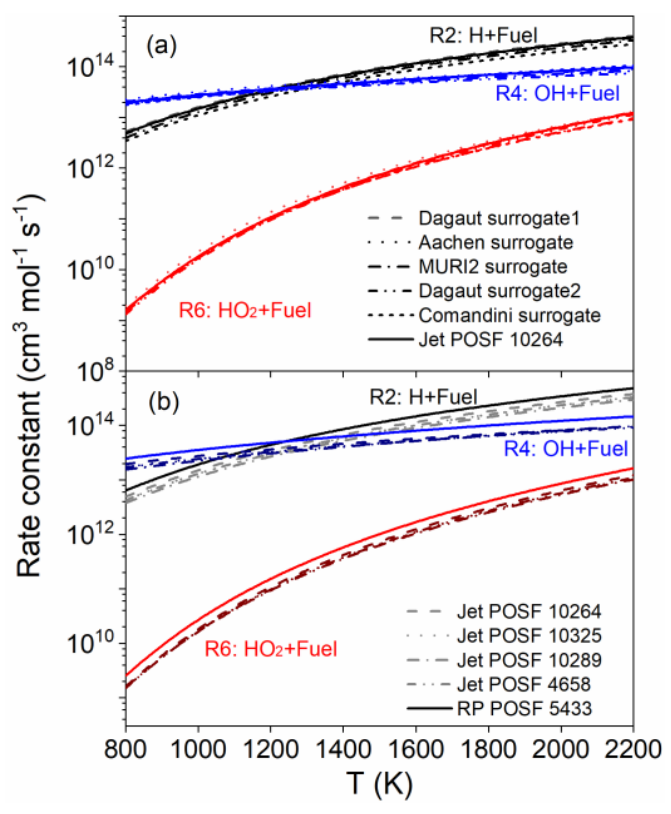

Fig. 3. (a) Estimated rate constants of R2, R4 and R6 in five jet fuel surrogate models (broken lines), i.e., Dagaut surrogate 1 (74\% $n$-decane/11\% $n$-propylcyclohexane/15\% $n$ propylbenzene in mol) [8], Aachen surrogate (77.2\% $n$-decane/22.8\% $1,2,4-$ trimethylbenzene in mol) [50], MURI2 surrogate (40.41\% $n$-dodecane/29.48\% isooctane/7.28\% 1,3,5-trimethylbenzene/22.83\% $n$-propylbenzene in mol) [51], Dagaut surrogate 2 (70\% $n$-decane/ 30\% n-propylbenzene in mol) [8] and Comandini surrogate (30\% $n$-butylbenzene/30\% $n$-propylcyclohexane/40\% $n$-decane in mol) [52], as well as Jet POSF 10264 (solid line); (b) Estimated rate constants of R2, R4 and R6 in four jet fuel models (broken lines), i.e., Jet POSF 10264, Jet POSF 10325, Jet POSF 10289 and Jet POSF 4658, as well as a rocket fuel (solid line), i.e. RP POSF 5433.

\subsection{Thermodynamic data of fuels}

Based on the characterization of real fuels [30], the functional groups of paraffinic $\mathrm{CH}_{3}, \mathrm{CH}_{2}$, $\mathrm{CH}$, $\mathrm{C}$, naphthenic $\mathrm{CH}, \mathrm{CH}_{2}$, aromatic $\mathrm{CH}$, aromatic $\mathrm{C}$ were identified and quantified, as well as the number of rings. Thermodynamic data, including enthalpy, entropy and heat capacity, of these functional groups are available in the literature [53,54], as shown in Table S8 in the Supplementary 
Material. Following the Benson group additivity method $[55,56]$, thermodynamic data of real fuels were obtained by adding the contribution of each individual functional group present in a real fuel molecule, based on Eqs. 2-4.

$$
\begin{aligned}
& \Delta_{f} H(298)=\sum_{i} G A V_{\Delta_{f} H}\left(X_{i}\right) \\
& S(298)=\sum_{i} G A V_{S}\left(X_{i}\right)-R \ln (\sigma) \\
& C_{p}(T)=\sum_{i} G A V_{C_{p}}\left(X_{i}\right)
\end{aligned}
$$

where $G A V_{\Delta_{f}}, G A V_{S}$ and $G A V_{C_{p}}$ represent the enthalpy, entropy and the heat capacity of each individual functional group, respectively; $X_{i}$ is the count of each functional group and $\sigma$ represents the symmetry number of a given species. In fuel mixtures, the symmetry number cannot be accurately determined, therefore, only the symmetry contribution from internal rotations of paraffinic $\mathrm{CH}_{3}$ was considered in this work, which may underestimate the symmetry number. Note that in Table S8 in the Supplementary Material, there are no naphthenic functional groups. The contributions of naphthenic groups were calculated by adding the contributions of paraffinic $\mathrm{CH}_{2}$ or $\mathrm{CH}$ and the six-membered ring. It should be noted that this implementation of GA does not consider the effects of the nonneighboring atom (e.g., gauche interactions, steric effects, etc.), which can influence the value of enthalpy. The importance of these effects depends on the structure of fuel molecules. A real-fuel mixture with a high composition of branched molecules has more gauche interactions. We compared the standard enthalpies of formation for 14 surrogate fuel mixtures of known composition based on the present GA method and THERM code, which neglect and incorporate these effects, respectively. Note, we employed THERM code to calculate the enthalpy of each pure component and added them up by multiplying their composition in surrogate fuel mixture. As listed in Table S10 in the Supplementary Material, the largest difference of standard enthalpy of formation (around $3 \mathrm{kcal} / \mathrm{mol}$ ) 
between the two methods is found for calculating PRF84, which contains a largest fraction of isooctane. This difference has little influence on the prediction of ignition delay times at high temperatures, while it has a minor influence $(0.18-0.69 \mathrm{~cm} / \mathrm{s})$ on the predictions of laminar flame speed.

In the HyChem approach [24], the standard enthalpy of formation was determined by the lower heating value, enthalpy of evaporation, and molecular weight. Heat capacity and entropy were estimated by defining a thermochemical surrogate that matches the mean molecular weight of each major class with that of the real fuel. Figure 4a offers a comparison of standard enthalpy of formation, heat capacity, and entropy of Jet POSF 10264, estimated by the present FGMech (orange bars) and HyChem (green bars) approaches [24]. The estimated thermodynamic data in this work are close to those estimated based on the HyChem approach [24]. Thermodynamic data for FACE gasoline fuels were first obtained in this work by adding the thermodynamic data of each individual component measured in fuel characterization experiments, as described in [57], and then obtained based on FGMech approach. Figure 4a shows that standard enthalpy of formation, heat capacity, and entropy of FACE A, estimated by the FGMech approach (purple bars), and those from detailed characterization (yellow bars), are similar. In addition, the thermodynamic data estimated in this work were compared for different surrogate mixtures and real fuels. Figure $4 \mathrm{~b}$ presents a comparison of standard enthalpy of formation and entropy for five jet fuel surrogates and a real jet fuel, i.e., Jet POSF 10264. The estimated thermodynamic data of various jet fuel surrogates are similar, and close to those of Jet POSF 10264. Combined with the similarities in stoichiometric parameters and kinetic rate constants observed in our work, the similar thermodynamic data of various jet fuel surrogates and real jet fuels imply the similar combustion characteristics of these fuels. 


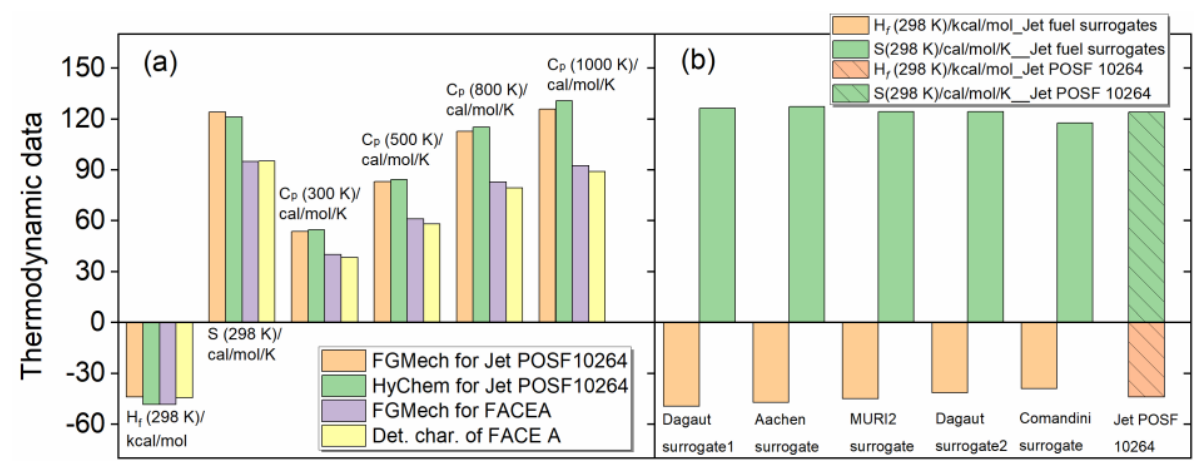

Fig. 4. (a) Comparison of standard enthalpy of formation, heat capacity and entropy of Jet POSF 10264 and FACE A, estimated by FGMech and methods in the literature (i.e. HyChem approach [24] for Jet POSF 10264 and detailed characterization of FACE A); (b) Comparison of standard enthalpy of formation and entropy among five jet fuel surrogates and Jet POSF 10264. See Fig. 3, caption, for formulation of jet fuel surrogates.

\subsection{Transport data}

In the HyChem approach [24], the transport data of real fuels were estimated to be equal to those of a $n$-alkane of the same carbon number. In this work, critical transport data were estimated based on the function group-based method. Lennard-Jones (LJ) 12-6 potential parameters, i.e., collision diameter $(\sigma)$ and potential well depth $(\varepsilon)$, play an important role in determining the transport properties such as thermal conductivity and mass diffusivity. This work followed the estimation method of Tee et al. [58], in which $\sigma$ and $\varepsilon$ were correlated with the critical pressure $\mathrm{P}_{\mathrm{c}}(\mathrm{atm})$ and temperature $\mathrm{T}_{\mathrm{c}}(\mathrm{K})$, as shown in Eqs. 5 and 6,

$$
\begin{aligned}
& \sigma\left(\frac{P_{c}}{T_{c}}\right)^{1 / 3}=a_{\sigma}-b_{\sigma} \omega \\
& \frac{\varepsilon}{k_{B} T_{c}}=a_{\varepsilon}+b_{\varepsilon} \omega
\end{aligned}
$$

where $\omega$ represents the acentric factor, and $a_{\sigma}, b_{\sigma}, a_{\varepsilon}$ and $b_{\varepsilon}$ are empirical coefficients. Based on [58], the following values were adopted in this work. 


$$
a_{\sigma}=2.3511, b_{\sigma}=0.3955, a_{\varepsilon}=0.8063, b_{\varepsilon}=0.6802
$$

The acentric factor $\omega$ was evaluated using Lee-Kesler vapor-pressure relations [59], as shown in Eq. 7,

$$
\omega=\frac{-\ln \left(P_{C}\right)-5.93+6.10 \theta^{-1}+1.29 \ln \theta-0.17 \theta^{6}}{15.25-15.69 \theta^{-1}-13.47 \ln \theta+0.44 \theta^{6}}
$$

where $\theta=\frac{T_{b}}{T_{c}}$, and $T_{b}$ is the boiling point at the ambient pressure.

Based on Eqs 5-7, given $T_{b}, T_{c}$ and $P_{c}$, the LJ potential parameters $\sigma$ and $\varepsilon$ can be obtained. This work adopted the Joback method [29] to estimate $T_{b}, T_{c}$ and $P_{c}$, which is also a group contribution method — calculating thermophysical and transport properties as a function of the sum of group parameters. $T_{b}, T_{c}$ and $P_{c}$ were calculated using Eqs 8-10, according to this method.

$$
\begin{aligned}
& T_{b}[K]=198.2+\sum T_{b, i}\left(X_{i}\right) \\
& T_{c}[K]=T_{b} /\left[0.584+0.965 \sum T_{c, i}\left(X_{i}\right)-\left(\sum T_{c, i}\left(X_{i}\right)\right)^{2}\right] \\
& P_{c}[\mathrm{bar}]=\left[0.113+0.0032 N_{a}-\sum P_{c, i}\left(X_{i}\right)\right]^{-2}
\end{aligned}
$$

where $N_{a}$ is the number of atoms in the molecular structure (including hydrogen atoms); $T_{b, i}, T_{c, i}$ and $P_{c, i}$ are the contributions of each group, obtained from [29] and listed in Table S9 in the Supplementary Material; $X_{i}$ is the count of each functional group.

For other transport parameters, polarizability $\alpha$ was estimated by an empirical additive formula according to Bosque and Sales [60], as shown in Eq. 11,

$$
\alpha=0.32+1.51 \times N(C)+0.17 \times N(H)+0.51 \times N(O)
$$

where $N(C), N(H)$ and $N(O)$ are the numbers of carbon, hydrogen and oxygen atoms, respectively. Dipole moment $(\mu)$ and rotational relaxation collision number at $298 \mathrm{~K}\left(Z_{\text {rot }}\right)$ were estimated to be zero and one for all the fuel mixtures, respectively. The former is justified because real fuels considered in 
this work are largely comprised of non-polar hydrocarbons with negligible dipole moments. When modeling fuels comprised of a large fraction of polar compounds (e.g., oxygenates), this dipole moment estimate should be re-evaluated.

Based on the present FGMech approach, kinetic models for 14 surrogate fuel mixtures and 12 real fuels were developed in this work, as listed in Table 1. Their functional group distributions, including both the mass fractions and counts, are provided in the Supplementary Material. The mass fractions of each group, as well as the molecular weight and branching index, were used to calculate the stoichiometric parameters, while the count of each group was used to estimate kinetic, thermodynamic and transport parameters. An example of Jet POSF 10264 was taken to illustrate how to obtain the rate constants of lumped reactions, thermodynamic and transport data of fuel, and this can be found in the Supplementary Material. The reaction mechanism, thermodynamic and transport data for each surrogate can be found in the Supplementary Material.

\subsection{Simulation methods}

All the simulations in this work were performed using Chemkin-Pro software [61]. Our simulation methods follow standard approaches for simulation shock tube reactors [62], flow reactor reactors [63], jet stirred reactors (JSR) [64], and premixed laminar flames [65]. Speciation profiles measured in shock tubes and flow reactors were simulated using a closed homogeneous batch reactor. Adiabatic and constant-pressure conditions were assumed for shock tube simulations, while constanttemperature and constant-pressure assumptions were adopted for flow reactor simulations. Jet-stirred reactor (JSR) experiments were simulated using a transient perfectly stirred reactor. The simulation end times were set as 20 times larger than the mean residence times to achieve a steady-state solution. Shock tube ignition delay time (IDT) simulations were also simulated using a closed homogeneous batch reactor with adiabatic and constant-volume conditions. The maximum temperature gradient (i.e. 
$\frac{\mathrm{dT}}{\mathrm{dt}}$ ), was used as criteria for calculating ignition delay times. This criteria correlates well with the maximum pressure rise rate or maximum $\mathrm{OH}^{*}$ signal often used in experiments to measure IDT. Flame speed simulations were performed using the premixed laminar-speed calculation module. Thermal diffusion and mixture-averaged transport equations were accounted for in the simulations. Grid independent results were achieved by assigning GRAD and CURV values to be 0.1 or smaller during the simulations.

\section{Model validation}

High temperature validation targets for 14 fuel surrogates and 12 real fuels are summarized in Table 1. These targets include speciation data from pyrolysis and oxidation, ignition delay times, and laminar flame speeds. HyChem models are only available for four of these real fuels (i.e., Jet POSF 10264, Jet POSF 10325, Jet POSF 10289 and RP POSF 5433), so comparisons are provided for those. HyChem models are not available for the remaining fuels because the HyChem modeling approach requires experimental pyrolysis data for each real fuel to develop the model, and these are not available for the majority of fuels in Table 1.

Unlike those of real fuels, the components and composition of surrogate mixtures in Table 1 are accurate. Therefore, the identification and quantification of functional groups are accurate, eliminating an important source of uncertainty. To this end, the present modeling approach was first validated against experimental data for various surrogate mixtures, and then validated against those of real fuels in the literature. In the FGMech input files, one pseudospecies represents a multi-component fuel mixture. For example, TPRF70 is the notation for a fuel mixture consisting of $35 \% n$-heptane $\left(\mathrm{NC}_{7} \mathrm{H}_{16}\right)$, $36.5 \%$ iso-octane $\left(\mathrm{IC}_{8} \mathrm{H}_{18}\right)$ and $28.5 \%$ toluene $\left(\mathrm{C}_{7} \mathrm{H}_{8}\right)$.

As mentioned previously, the FGMech approach was tested on two different base chemistry models. FGMech coupled with AramcoMech 2.0 [27] is denoted as FGMech-Aramco, while that 
coupled with USC Mech II [28] is FGMech-USC. Kinetic models developed in the literature for surrogate mixtures and real fuels were also selected to compare against the validation targets, to better examine the model performance of the FGMech approach.

Table 1 High-temperature validation targets for this FGMech approach

\begin{tabular}{|c|c|c|c|c|c|c|}
\hline Fuel nomenclature & Exp. type & Mixture & $\mathbf{P}(\mathbf{a t m})$ & $\mathbf{T}(\mathbf{K})$ & $\phi$ & Ref. \\
\hline NC7TOL & Pyrolysis & $\mathrm{NC}_{7} \mathrm{H}_{16} / \mathrm{C}_{7} \mathrm{H}_{8} / \mathrm{N}_{2}$ & 1 & $860-1250$ & $\infty$ & [66] \\
\hline PRF70 & Pyrolysis & $\mathrm{NC}_{7} \mathrm{H}_{16} / \mathrm{IC}_{8} \mathrm{H}_{18} / \mathrm{N}_{2}$ & 1 & $800-1200$ & $\infty$ & [66] \\
\hline \multirow{2}{*}{ PRF84 } & Ignition delay & $\mathrm{NC}_{7} \mathrm{H}_{16} / \mathrm{IC}_{8} \mathrm{H}_{18} / \mathrm{O}_{2} / \mathrm{Ar}$ & 2 & $1261-1533$ & 1.0 & [67] \\
\hline & Flame speed & $\mathrm{NC}_{7} \mathrm{H}_{16} / \mathrm{IC}_{8} \mathrm{H}_{18} /$ air & $1-6$ & 358 & $0.8-1.6$ & [68] \\
\hline TPRF70 & Pyrolysis & $\mathrm{NC}_{7} \mathrm{H}_{16} / \mathrm{IC}_{8} \mathrm{H}_{18} / \mathrm{C}_{7} \mathrm{H}_{8} / \mathrm{Ar}$ & 1 & $830-1250$ & $\infty$ & [69] \\
\hline TPRF80 & Pyrolysis & $\mathrm{NC}_{7} \mathrm{H}_{16} / \mathrm{IC}_{8} \mathrm{H}_{18} / \mathrm{C}_{7} \mathrm{H}_{8} / \mathrm{Ar}$ & 1 & $830-1220$ & $\infty$ & [66] \\
\hline TPRF85 & Flame speed & $\mathrm{NC}_{7} \mathrm{H}_{16} / \mathrm{IC}_{8} \mathrm{H}_{18} / \mathrm{C}_{7} \mathrm{H}_{8} /$ air & $1-6$ & 358 & $0.8-1.6$ & [68] \\
\hline CTPRF95 & Ignition delay & $\mathrm{NC}_{7} \mathrm{H}_{16} / \mathrm{IC}_{8} \mathrm{H}_{18} / \mathrm{C}_{7} \mathrm{H}_{8} / \mathrm{C}_{6} \mathrm{H}_{12} /$ air & $10-20$ & $1027-1400$ & $0.5-2.0$ & [70] \\
\hline $\mathrm{C}_{9} \mathrm{H}_{20} \mathrm{NHD}$ & Ignition delay & $\mathrm{NC}_{10} \mathrm{H}_{22} / \mathrm{NC}_{6} \mathrm{H}_{14} / \mathrm{air}$ & 9 & $1000-1700$ & 1.0 & [71] \\
\hline $\mathrm{C}_{9} \mathrm{H}_{19} \mathrm{BD}$ & Ignition delay & $\mathrm{NC}_{10} \mathrm{H}_{22} / \mathrm{C}_{6} \mathrm{H}_{6} /$ air & 9 & $1000-1700$ & 1.0 & [71] \\
\hline $\mathrm{C}_{10} \mathrm{H}_{20} \mathrm{~A}$ & Flame speed & $\mathrm{NC}_{10} \mathrm{H}_{22} / 1,2,4-\mathrm{TMB} /$ air & 1 & 400 & $0.7-1.4$ & [72] \\
\hline $\mathrm{C}_{10} \mathrm{H}_{20} \mathrm{D}$ & Flame speed & $\mathrm{NC}_{10} \mathrm{H}_{22} / n-\mathrm{PCH} / \mathrm{C}_{6} \mathrm{H}_{5} \mathrm{C}_{3} \mathrm{H}_{7} /$ air & $1-10$ & $400-473$ & $0.7-1.3$ & [73] \\
\hline $\mathrm{C}_{10} \mathrm{H}_{18} \mathrm{C}$ & Flame speed & $\mathrm{NC}_{10} \mathrm{H}_{22} / n-\mathrm{PCH} / \mathrm{C}_{6} \mathrm{H}_{5} \mathrm{C}_{4} \mathrm{H}_{9} /$ air & 1 & 403 & $0.6-1.6$ & [52] \\
\hline $\mathrm{C}_{10} \mathrm{H}_{19} \mathrm{D} 2$ & Ignition delay & $\mathrm{NC}_{10} \mathrm{H}_{22} / \mathrm{C}_{6} \mathrm{H}_{5} \mathrm{C}_{3} \mathrm{H}_{7} / \mathrm{O}_{2} / \mathrm{Ar}$ & 6 & $1250-1700$ & $0.5-1.3$ & [74] \\
\hline \multirow{3}{*}{$\mathrm{C}_{10} \mathrm{H}_{19} \mathrm{M}$} & Oxidation & $\mathrm{NC}_{12} \mathrm{H}_{26} / \mathrm{IC}_{8} \mathrm{H}_{18} / 1,3,5-\mathrm{TMB} / \mathrm{O}_{2} / \mathrm{Ar}$ & 20 & $879-1733$ & $0.46-1.85$ & {$[75]$} \\
\hline & Ignition delay & $\mathrm{NC}_{12} \mathrm{H}_{26} / \mathrm{IC}_{8} \mathrm{H}_{18} / 1,3,5$-TMB/air & 20 & $1000-1223$ & 1.0 & [51] \\
\hline & Flame speed & $\mathrm{NC}_{12} \mathrm{H}_{26} / \mathrm{IC}_{8} \mathrm{H}_{18} / 1,3,5$-TMB/air & $1-3$ & 400 & $0.7-1.3$ & [76] \\
\hline FACEA & Ignition delay & FACE A/air & $20-40$ & $1000-1200$ & $0.5-1.0$ & [33] \\
\hline \multirow{2}{*}{ FACEC } & Ignition delay & FACE C/air & $20-40$ & $1000-1200$ & $0.5-1.0$ & [33] \\
\hline & Flame speed & FACE C/air & $1-6$ & 358 & $0.8-1.6$ & [68] \\
\hline FACEF & Ignition delay & FACE F/air & $20-40$ & $1000-1200$ & $0.5-1.0$ & [77] \\
\hline FACEG & Ignition delay & FACE G/air & $20-40$ & $1000-1200$ & $0.5-1.0$ & [77] \\
\hline FACEI & Ignition delay & FACE I/air & $20-40$ & $1000-1200$ & $0.5-1.0$ & [78] \\
\hline FACEJ & Ignition delay & FACE J/air & $20-40$ & $1000-1200$ & $0.5-1.0$ & [78] \\
\hline \multirow{3}{*}{ POSF10264 } & Pyrolysis & Jet POSF 10264/Ar & $12-40$ & $1000-1400$ & $\infty$ & [79] \\
\hline & Ignition delay & Jet POSF $10264 / \mathrm{O}_{2} / \mathrm{Ar}$ & $12-40$ & $1000-1400$ & $0.5-1.0$ & [79] \\
\hline & Flame speed & Jet POSF 10264/air & 1 & 403 & $0.8-1.4$ & [24] \\
\hline \multirow{4}{*}{ POSF10325 } & Pyrolysis & Jet POSF 10325/Ar & $12-40$ & $1000-1400$ & $\infty$ & [79] \\
\hline & Oxidation & Jet POSF $10325 / \mathrm{O}_{2} / \mathrm{N}_{2}$ & 1 & 1030 & 1.0 & [24] \\
\hline & Ignition delay & Jet POSF $10325 / \mathrm{O}_{2} / \mathrm{Ar}$ & $12-40$ & $1000-1400$ & $0.5-1.0$ & [79] \\
\hline & Flame speed & Jet POSF 10325/air & 1 & 403 & $0.8-1.4$ & [24] \\
\hline \multirow{3}{*}{ POSF10289 } & Pyrolysis & Jet POSF 10289/Ar & $12-40$ & $1000-1400$ & $\infty$ & [79] \\
\hline & Ignition delay & Jet POSF $10289 / \mathrm{O}_{2} / \mathrm{Ar}$ & $12-40$ & $1000-1400$ & $0.5-1.0$ & [79] \\
\hline & Flame speed & Jet POSF 10289/air & 1 & 403 & $0.8-1.4$ & [24] \\
\hline \multirow{3}{*}{ POSF4658 } & Oxidation & Jet POSF $4658 / \mathrm{O}_{2} / \mathrm{Ar}$ & 20 & $879-1733$ & $0.46-1.85$ & [75] \\
\hline & Ignition delay & Jet POSF 4658/air & 20 & $1000-1380$ & $0.25-1.5$ & [80] \\
\hline & Flame speed & Jet POSF 4658/air & $1-3$ & $350-470$ & $0.7-1.3$ & [76] \\
\hline \multirow{3}{*}{ POSF5433 } & Pyrolysis & RP POSF 5433/Ar & 13 & 1284 & $\infty$ & [24] \\
\hline & Ignition delay & $\mathrm{RP}$ POSF $5433 / \mathrm{O}_{2} / \mathrm{Ar}$ & 1 & $1200-1600$ & $0.7-1.1$ & [24] \\
\hline & Flame speed & RP POSF 5433/air & 1 & 403 & $0.8-1.4$ & [24] \\
\hline POSF4734 & Flame speed & S-8 POSF 4734/air & $1-3$ & 400 & $0.7-1.4$ & [76] \\
\hline
\end{tabular}

\subsection{Validation against experimental data of surrogate fuel mixtures}

As shown in Table 1, validation targets for surrogate fuel mixtures can be divided into gasoline and jet fuels. Gasoline surrogate mixtures mainly consist of $\mathrm{NC}_{7} \mathrm{H}_{16}, \mathrm{IC}_{8} \mathrm{H}_{18}, \mathrm{C}_{7} \mathrm{H}_{8}$ and cyclohexane $\left(\mathrm{C}_{6} \mathrm{H}_{12}\right)$, while jet fuel surrogates mainly consist of $n$-decane $\left(\mathrm{NC}_{10} \mathrm{H}_{22}\right), n$-dodecane $\left(\mathrm{NC}_{12} \mathrm{H}_{24}\right), \mathrm{IC}_{8} \mathrm{H}_{18}$, $n$-propylcyclohexane $\left(n\right.$-PCH), n-propylbenzene $\left(\mathrm{C}_{6} \mathrm{H}_{5} \mathrm{C}_{3} \mathrm{H}_{7}\right), n$-butylbenzene $\left(\mathrm{C}_{6} \mathrm{H}_{5} \mathrm{C}_{4} \mathrm{H}_{9}\right), 1,3,5$ - 
trimethylbenzene (1,3,5-TMB), 1,2,4-trimethylbenzene (1,2,4-TMB), etc. Validation results of the present FGMech against these experimental data are presented below.

\subsubsection{Gasoline surrogate fuel mixtures}

Pyrolysis speciation data are used to constrain stoichiometric parameters and $\mathrm{k}_{1}-\mathrm{k}_{3}$ in the HyChem approach [24]. These parameters are sensitive to mole fractions of $\mathrm{CH}_{4}, \mathrm{C}_{2} \mathrm{H}_{4}, \mathrm{C}_{3} \mathrm{H}_{6}, \mathrm{C}_{4} \mathrm{H}_{8}$ isomers, $\mathrm{C}_{6} \mathrm{H}_{6}$ and $\mathrm{C}_{7} \mathrm{H}_{8}$. The ability of FGMech to accurately predict pyrolysis speciation data is a validation of its stoichiometric and $\mathrm{k}_{1}-\mathrm{k}_{3}$ kinetic parameters. Shao et al. [66,69] recently reported pyrolysis speciation data of gasoline surrogates in both a flow reactor and a JSR at atmospheric pressure. Figure 5 presents the measured and predicted mole fractions of small intermediates in the JSR pyrolysis of a primary reference fuel (i.e. PRF70). Comparison of the measured and predicted speciation data in the pyrolysis of other binary and tertiary gasoline surrogate mixtures can be found in Figs. S1-S3 in the Supplementary Material. For better comparison, a detailed gasoline surrogate model, developed by Sarathy et al. [77], (named the 2016 Sarathy model), was selected to evaluate the FGMech approach.

As shown in Figs. 5 and S1-S3, FGMech-Aramco and FGMech-USC reproduce the peak mole fractions of the $\mathrm{C}_{1}-\mathrm{C}_{4}$ intermediates, and they are comparable to the performance of the 2016 Sarathy model [77]. FGMech-Aramco better captures the mole fraction profiles of $\mathrm{C}_{4} \mathrm{H}_{8}$ isomers, while the FGMech-USC better captures the yield of $\mathrm{C}_{2} \mathrm{H}_{2}$. However, both FGMechs over-predict the formation of $\mathrm{CH}_{4}$ and $\mathrm{C}_{6} \mathrm{H}_{6}$, especially at initial temperatures (over 800-1000 K, see Figs. $5 \mathrm{~b}$ and $5 \mathrm{f}$ ). Below $1000 \mathrm{~K}$, their predicted stoichiometric parameters may be less reliable since the datasets used for their MLR model training were from pyrolysis experimental data above $1000 \mathrm{~K}$ [25]. The overestimated stoichiometric parameters for $\mathrm{CH}_{4}$ and $\mathrm{C}_{6} \mathrm{H}_{6}$ may cause FGMech to predict the formation of these species at temperatures below their experimentally measured appearance. The predicted formation of 
$\mathrm{C}_{6} \mathrm{H}_{6}$ by both $\mathrm{FGMechs}$ first increases $(800-950 \mathrm{~K})$, and then decreases $(950-1050 \mathrm{~K})$ during the conversion of fuel, as shown in Fig. 5f. This results from the competition between the unimolecular decomposition reaction $\mathrm{R} 1$ and $\mathrm{H}$-atom abstraction reaction $\mathrm{R} 2$. For PRF70, the molecular formula is $\mathrm{C}_{8} \mathrm{H}_{18}(\mathrm{~m}=8, \mathrm{n}=18)$. Based on the balances of $\mathrm{C}$ and $\mathrm{H}$ elements, $b_{d}$ in $\mathrm{R} 1$ is calculated to be zero while $b_{a}$ in $\mathrm{R} 2-\mathrm{R} 7$ is not. Therefore, $\mathrm{C}_{6} \mathrm{H}_{6}$ is not present in the unimolecular decomposition reaction $\mathrm{R} 1$, while it is present in the $\mathrm{H}$-atom abstraction reaction $\mathrm{R} 2$. Once fuel reactivity is initiated at lower temperatures, $\mathrm{C}_{6} \mathrm{H}_{6}$ is generated via R2, simultaneously with the consumption of PRF70 (800 - 950 K). As the temperature increases, R1 becomes more competitive than R2 (950 - $1050 \mathrm{~K})$. Since no $\mathrm{C}_{6} \mathrm{H}_{6}$ could be produced directly via $\mathrm{R} 1$, the formation of $\mathrm{C}_{6} \mathrm{H}_{6}$ decreases. Above $1050 \mathrm{~K}$, PRF70 is completely converted and the small intermediates are accumulated. The secondary reactions become increasingly important in the formation of $\mathrm{C}_{6} \mathrm{H}_{6}$ and contribute to the second increase of $\mathrm{C}_{6} \mathrm{H}_{6}$. The stoichiometric parameters obtained by MLR correlations are more reliable above $1050 \mathrm{~K}$, resulting in fewer discrepancies between the predicted and measured results, as shown in Fig. $5 \mathrm{f}$. The original formulation of FGMech based on HyChem is probably not suitable for fuels that contain no aromatic component, since $\mathrm{C}_{6} \mathrm{H}_{6}$ and $\mathrm{C}_{7} \mathrm{H}_{8}$ should not be considered as direct pyrolysis products from these fuels. Therefore, we introduced two additional parameters $\omega$ and $\theta$ to correct $\chi$ and (1- $\chi)$, i.e. $\omega \chi$ and $\theta(1-\chi)$. When there are aromatic components present in a fuel mixture, $\omega$ and $\theta$ are both set to be 1 , while when there is no aromatic component, they are both set to be 0 . For PRF70, $\omega$ and $\theta$ are both set to be 0 , eliminating the formation of $\mathrm{C}_{6} \mathrm{H}_{6}$ and $\mathrm{C}_{7} \mathrm{H}_{8}$ in $\mathrm{R} 1-\mathrm{R} 7$. The predicted results by the updated FGMech-Aramco model are shown in Fig. 5, dash dot lines. It is observed that the initial overestimation of $\mathrm{C}_{6} \mathrm{H}_{6}$ yield disappears while little influence was found on the predictions of other products. The overestimation of $\mathrm{C}_{6} \mathrm{H}_{6}$ at $\mathrm{T}>1050 \mathrm{~K}$ shown in Fig. $5 \mathrm{f}$ mainly results from the base mechanism, since when we adopted 2016 Sarathy model as the base model, the updated FGMech- 
Sarathy model predicts the $\mathrm{C}_{6} \mathrm{H}_{6}$ profile quite well.

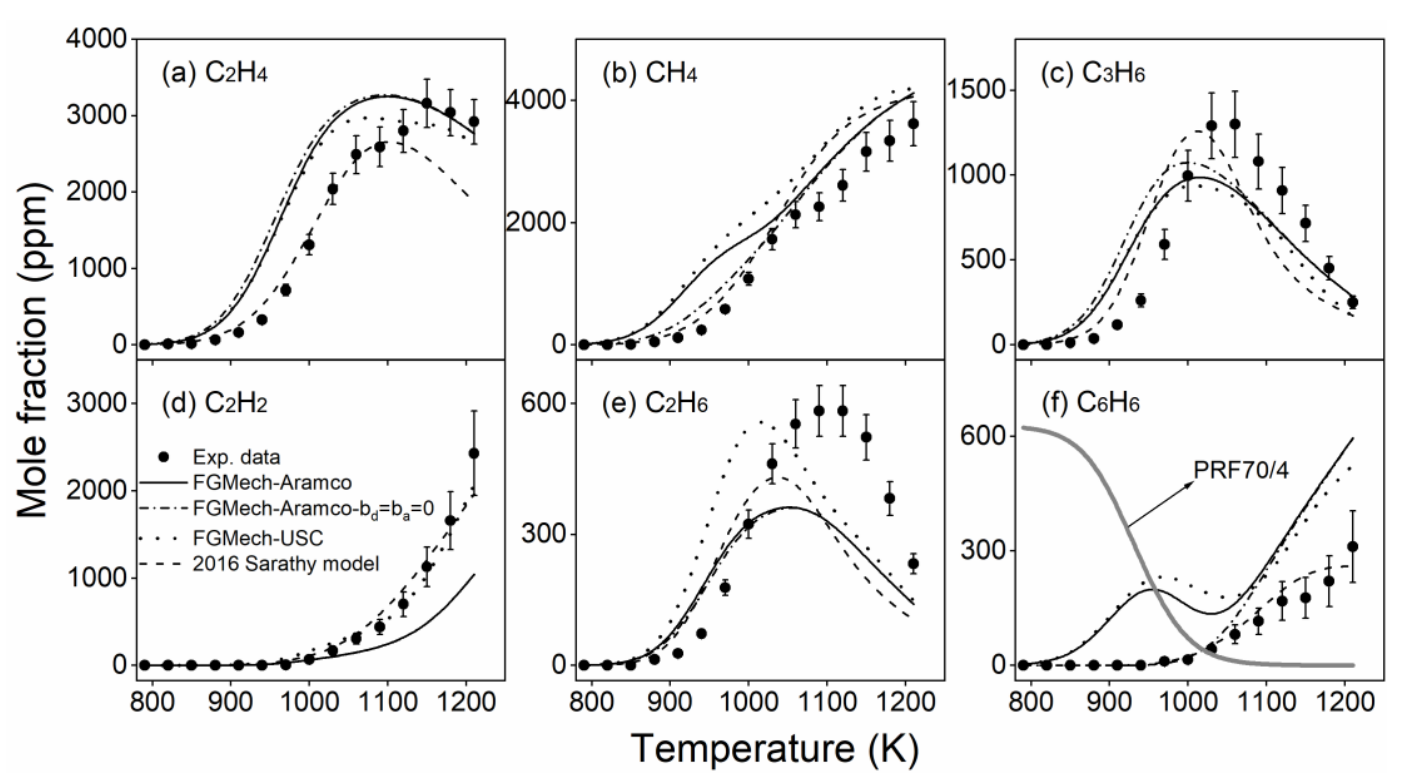

Fig. 5. Comparison of measured (symbols) [66] and predicted (lines) mole fractions of (a) ethylene $\left(\mathrm{C}_{2} \mathrm{H}_{4}\right)$, (b) methane $\left(\mathrm{CH}_{4}\right)$, (c) propene $\left(\mathrm{C}_{3} \mathrm{H}_{6}\right)$, (d) acetylene $\left(\mathrm{C}_{2} \mathrm{H}_{2}\right)$, (e) ethane $\left(\mathrm{C}_{2} \mathrm{H}_{6}\right)$ and (f) benzene $\left(\mathrm{C}_{6} \mathrm{H}_{6}\right)$ in JSR pyrolysis of $0.25 \%$ PRF70 (32.6\% $n$-heptane/67.4\% iso-octane) in $\mathrm{N}_{2}$ at $1 \mathrm{~atm}$ and $\tau=1 \mathrm{~s}$. Solid, dotted, dash dot and dashed lines represent predicted results of present FGMech-Aramco, FGMech-USC, updated FGMech-Aramco (see text), and detailed model [77], respectively.

In addition to pyrolysis speciation data, FGMech was also validated against the ignition delay times and laminar flame speeds of gasoline surrogates. Figure 6 presents validation results for two binary gasoline mixtures, i.e., PRF84 and PRF85. Ignition delay times of PRF84 predicted by both FGMechs are close to those of the detailed Sarathy model [77], and all three models slightly overpredict the measured ignition delay times [67]. Figure 6b shows laminar flame speed results for PRF 85. Both FGMech-Aramco and the reduced Li model [81] capture the experimental data; the FGMechUSC model under-predicts flame speeds at equivalence ratios between 1.1-1.3, while reproducing the experimental data at other equivalence ratios. 

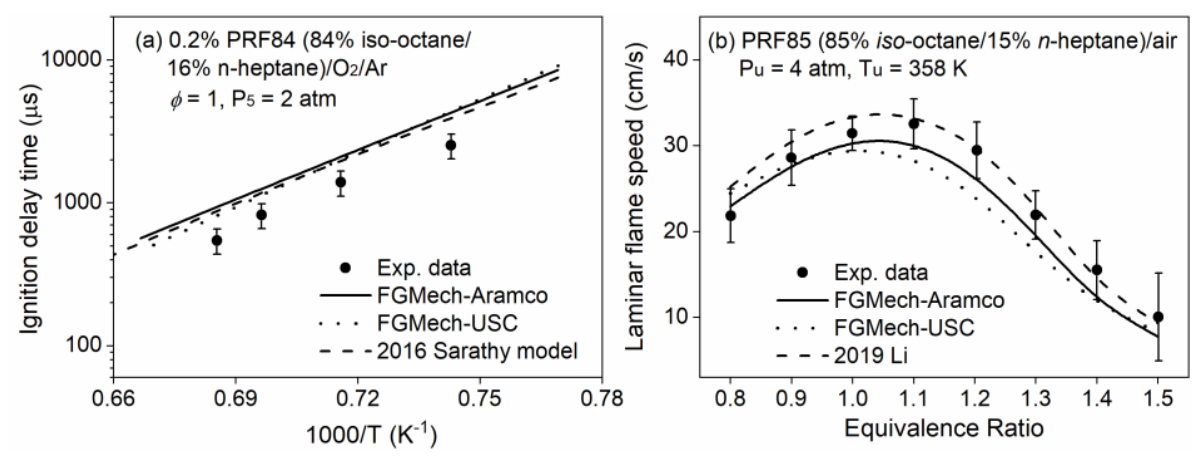

Fig. 6. (a) Comparison of measured (symbols) [67] and predicted (lines) ignition delay times for PRF84 (16\% $n$-heptane/84\% iso-octane) $/ \mathrm{O}_{2} /$ Ar mixture $(\phi=1.0)$ in a shock tube at $\mathrm{P}_{5}=2$ atm; (b) measured (symbols) [68] and predicted (lines) laminar flame speeds for PRF85 $(15 \%$-heptane $/ 85 \%$ iso-octane $) /$ air at $\mathrm{T}_{\mathrm{u}}=358 \mathrm{~K}$ and $\mathrm{P}_{\mathrm{u}}=4 \mathrm{~atm}$. Solid, dotted, and dashed lines represent predicted results of the present FGMech-Aramco, FGMech-USC and previous models by Sarathy [77,81] and Li [64], respectively.

In addition to binary gasoline surrogates, this work also developed tertiary and quaternary gasoline surrogate models based on the FGMech approach. The quaternary gasoline surrogate (named CTPRF95), consists of cyclohexane, toluene, $n$-heptane, and iso-octane, and its research octane number is 95. FGMechs for CTPRF95 were validated against ignition delay times [70] measured in a shock tube, covering a pressure range of 10-20 bar and a temperature range of 1027-1400 K. As shown in Fig. 7 and Fig. S4 in the Supplementary Material, the performance of both FGMechs is comparable to the detailed model [77] under various equivalence ratio conditions. The tertiary gasoline surrogate consists of $17.6 \% n$-heptane, $77.4 \%$ iso-octane and $5 \%$ toluene, and is denoted as TPRF 85 . Validation results against the laminar flame speeds over 1-6 atm can be found in Fig. S5 in the Supplementary Material. Both FGMechs reproduce the laminar flame speeds well under fuel-lean and stoichiometric conditions, while under-predicting measurements under rich conditions. In contrast, the reduced Li model [81] captures laminar flame speeds under rich conditions, while over-predicting measurements under fuel-lean conditions. 

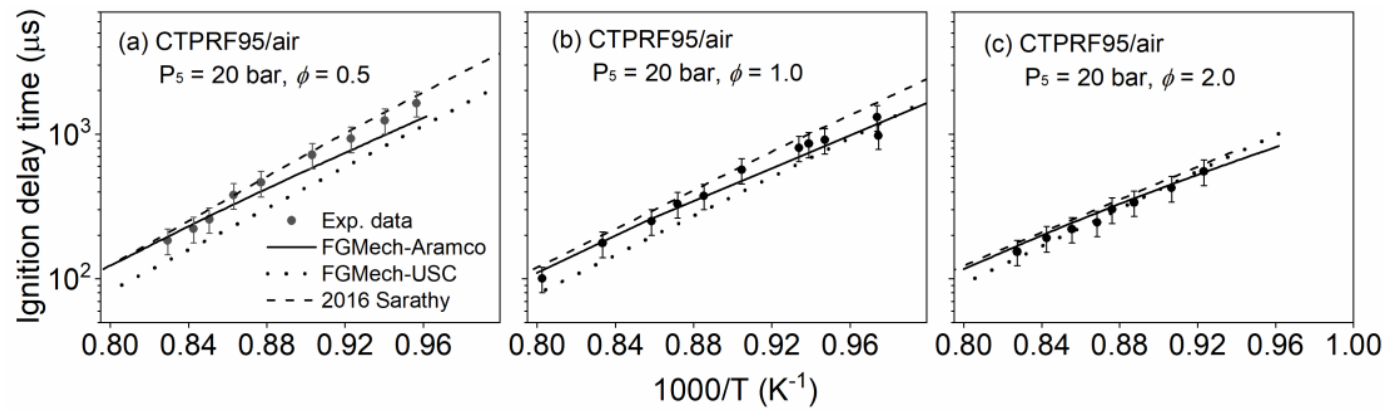

Fig. 7. Comparison of measured (symbols) [70] and predicted (lines) ignition delay times for CTRF (11.85\% cyclohexane/11\% $n$-heptane/30.07\% iso-octane/40.08\% toluene)/air mixtures in a shock tube at $\mathrm{P}_{5}=20$ bar and $\phi=0.5-2.0$. Solid, dotted and dashed lines represent predicted results of present FGMech-Aramco, FGMech-USC and previous model [77], respectively.

\subsubsection{Jet fuel surrogate mixtures}

This work also modeled jet fuel surrogate mixtures based on the FGMech approach. Among them, the MURI2 surrogate consists of $n$-dodecane, iso-octane, 1,3,5-trimethylbenzene, and $n$ propylbenzene. The FGMechs for the MURI2 surrogate were validated against speciation data measured in a shock tube at $\mathrm{P}_{5}=20$ atm and $\phi=0.47$ and 1.85 [75]. Validation results can be found in Fig. 8 and Fig. S6 in the Supplementary Material. A detailed model for MURI2, developed by Malewicki et al. [75], (named the 2013 Malewicki model) is also compared against these experimental data. FGMech-USC captures the oxidation rate of $\mathrm{O}_{2}$ under both lean and rich conditions (see Fig. 8a and Fig. S6a in the Supplementary Material) better than the FGMech-Aramco. To better capture the oxidation rate of $\mathrm{O}_{2}$ under fuel-rich conditions, the FGMech was merged into the base mechanism from the Malewicki model [75] (denoted the FGMech-Malewicki). As seen in Fig. S6a in the Supplementary Material, the FGMech-Malewicki model predicts the temperature window of $\mathrm{O}_{2}$ consumption and formation of other intermediates well. By comparing different FGMech models, it was found that the base mechanism played a critical role in determining fuel oxidation rate and 
temperature windows of intermediates formation. All FGMechs reasonably capture the peak mole fractions of most intermediates, i.e., $\mathrm{C}_{2} \mathrm{H}_{4}, \mathrm{C}_{3} \mathrm{H}_{6}, \mathrm{C}_{4} \mathrm{H}_{8}-1, \mathrm{C}_{2} \mathrm{H}_{2}, \mathrm{C}_{2} \mathrm{H}_{6}$, indicating that most of the stoichiometric parameters obtained from the MLR correlations were reasonable. The over-estimation of $\mathrm{CH}_{4}$ and $\mathrm{IC}_{4} \mathrm{H}_{8}$ by $\mathrm{FG}$ models indicates that the stoichiometric parameters $\gamma$ and $\lambda_{4, \mathrm{i}}$ may be overpredicted.
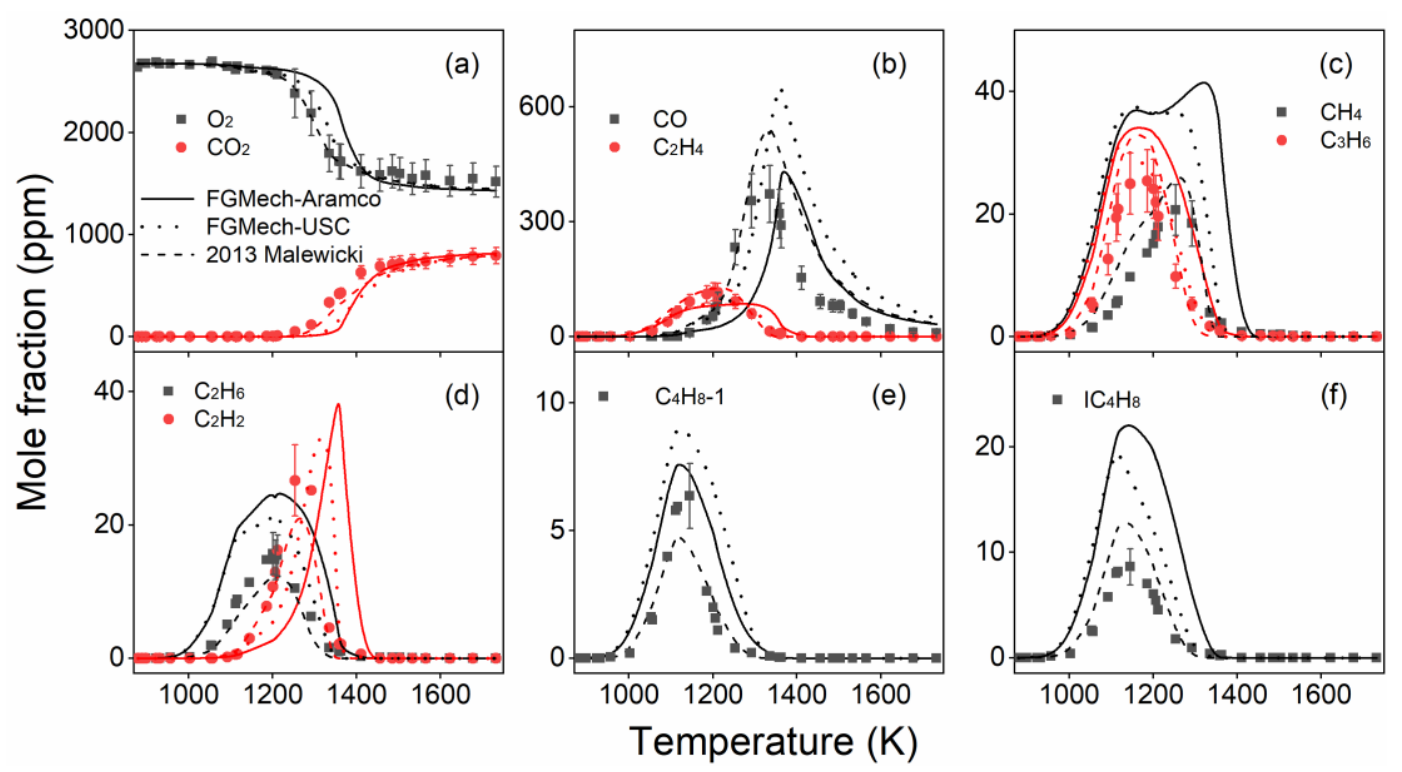

Fig. 8. Comparison of measured (symbols) [75] and predicted (lines) mole fractions of (a) $\mathrm{O}_{2}$ and $\mathrm{CO}_{2}$, (b) $\mathrm{CO}$ and $\mathrm{C}_{2} \mathrm{H}_{4}$, (c) $\mathrm{CH}_{4}$ and $\mathrm{C}_{3} \mathrm{H}_{6}$, (d) $\mathrm{C}_{2} \mathrm{H}_{6}$ and $\mathrm{C}_{2} \mathrm{H}_{2}$, (e) $\mathrm{C}_{4} \mathrm{H}_{8}-1$ and (f) $\mathrm{IC}_{4} \mathrm{H}_{8}$ in shock tube oxidation of 84.68 ppm MURI2 (40.41\% n-dodecane/29.48\% iso-octane/7.28\% 1,3,5-trimethylbenzene $/ 22.83 \% n$-propylbenzene) in Ar at 20 atm and $\phi=0.47$. Solid, dotted and dashed lines represent predicted results of the present FGMech-Aramco, FGMech-USC and previous model [75], respectively.

Ignition delay times of jet fuel surrogates were also used to validate the FGmech models for MURI2, as well as other surrogate fuels. For binary jet fuel mixtures $\mathrm{C}_{9} \mathrm{H}_{19} \mathrm{BD}\left(20 \% \mathrm{C}_{6} \mathrm{H}_{6} / 80 \%\right.$ $\left.\mathrm{NC}_{10} \mathrm{H}_{22}\right)$ and $\mathrm{C}_{9} \mathrm{H}_{20} \mathrm{NHD}\left(20 \% \mathrm{NC}_{6} \mathrm{H}_{14} / 80 \% \mathrm{NC}_{10} \mathrm{H}_{22}\right)$, the FGMech models were validated against the ignition delay times measured in a shock tube over 1000-1700 K and at 9 atm [71]; these predicted 
results were compared with those of a detailed model, i.e., JetSurf 2.0 model [82]. For another binary jet surrogate, i.e., $\mathrm{C}_{10} \mathrm{H}_{19} \mathrm{D} 2\left(70 \% \mathrm{NC}_{10} \mathrm{H}_{22} / 30 \% \mathrm{C}_{6} \mathrm{H}_{5} \mathrm{C}_{3} \mathrm{H}_{7}\right)$, the FGMech models were validated against the ignition delay times measured by Steil et al. [74] at 6 atm. MURI2 is a quaternary jet surrogate, and the ignition delay times of MURI2/air measured by Dooley et al. [51] at 20 atm were used to validate the FGMech models. For comparison, a detailed mechanism developed by Malewicki et al. [75] was selected to predict the ignition delay times of MURI2 and $\mathrm{C}_{10} \mathrm{H}_{19} \mathrm{D} 2$. Figure 9 presents the validation results of the present FG models against ignition delay times of four jet fuel surrogates. In general, the FGMech-USC (dotted lines) predicts lower ignition delay times than the FGMechAramco (see Figs. 9(a, b, d)) and better captures experimental data at higher temperatures (>1100 K). In contrast, below $1100 \mathrm{~K}$ (seen from Fig. 9c), the FGMech-Aramco predicts lower ignition delay times than FGMech-USC and better captures the experimental data. Both FGMechs have comparable performance, compared with the results predicted by the detailed models.

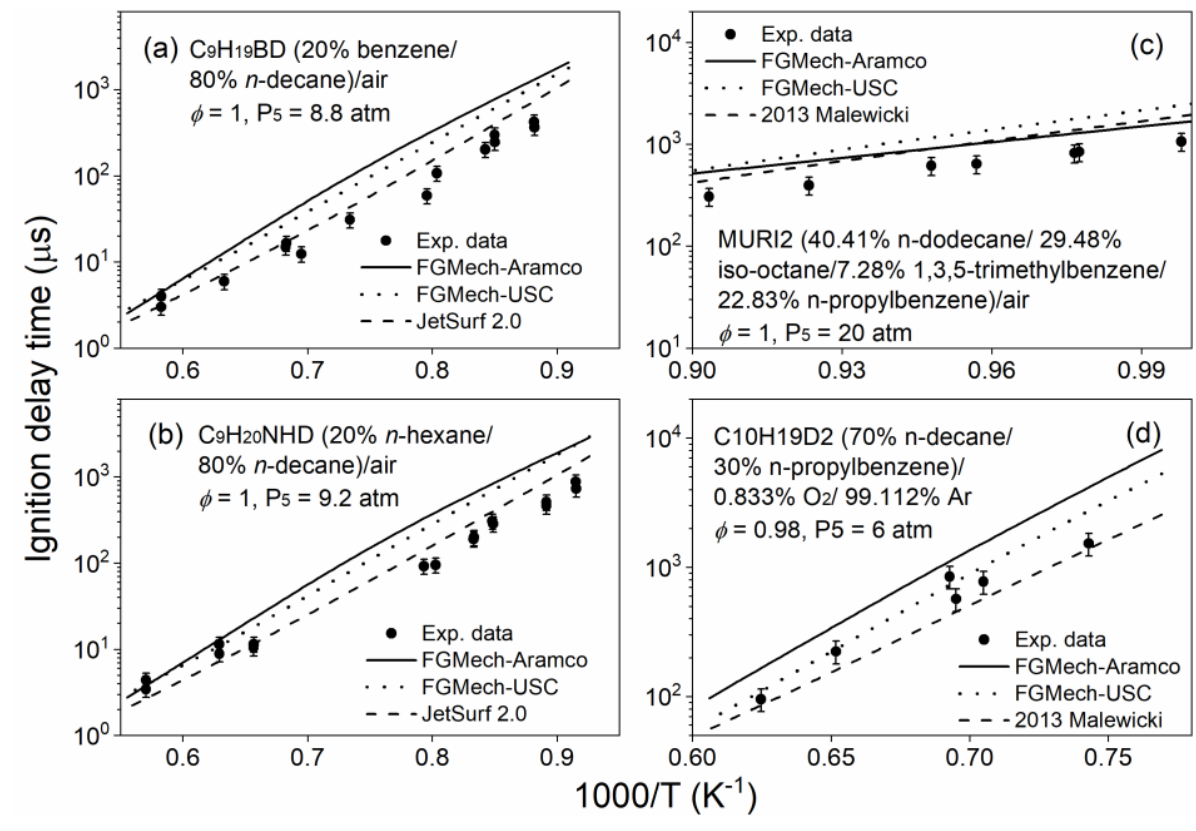

Fig. 9. Comparison of measured (symbols) and predicted (lines) ignition delay times for (a) $\mathrm{C}_{9} \mathrm{H}_{19} \mathrm{BD} /$ air at $\phi=1$ and $\mathrm{P}_{5}=8.8 \mathrm{~atm}[71]$, (b) NHD13/air at $\phi=1$ and $\mathrm{P}_{5}=9.2 \mathrm{~atm}[71]$, (c) MURI2/air at $\phi=1$ and $\mathrm{P}_{5}=20 \mathrm{~atm}$ [51] and (d) $\mathrm{C}_{10} \mathrm{H}_{19} \mathrm{D} 4 / 0.833 \% \mathrm{O}_{2} / 99.112 \% \mathrm{Ar}$ at $\phi=0.98$ and $\mathrm{P}_{5}=6 \mathrm{~atm}[74]$. Solid, dotted and dashed lines represent predicted results of 
FGMech-Aramco, FGMech-USC and previous detailed (i.e. Malewicki [75], and JetSurf 2.0 [82]) models, respectively.

To further validate the FGMech approach under higher temperature conditions, laminar flame speed data were incorporated. Figure 10 and Fig. S7 in the Supplementary Material compare the FGMechs and literature models [52,83] against the laminar flame speed data, including the measurement of the Comandini surrogate (named $\mathrm{C}_{10} \mathrm{H}_{18} \mathrm{C}$ ) [52], the Dagaut surrogate [73] (named $\mathrm{C}_{10} \mathrm{H}_{20} \mathrm{D}$ ), the MURI2 surrogate [76] and the Aachen surrogate (named $\mathrm{C}_{10} \mathrm{H}_{20} \mathrm{~A}$ ) [72] at various unburned temperatures, pressures, and equivalence ratios. Compared with the detailed models $[50,52,83]$, the present FGMech models show comparable predictability. Under lean and high pressure conditions, the FGMech models show superior performance, as shown in Fig. 10d.
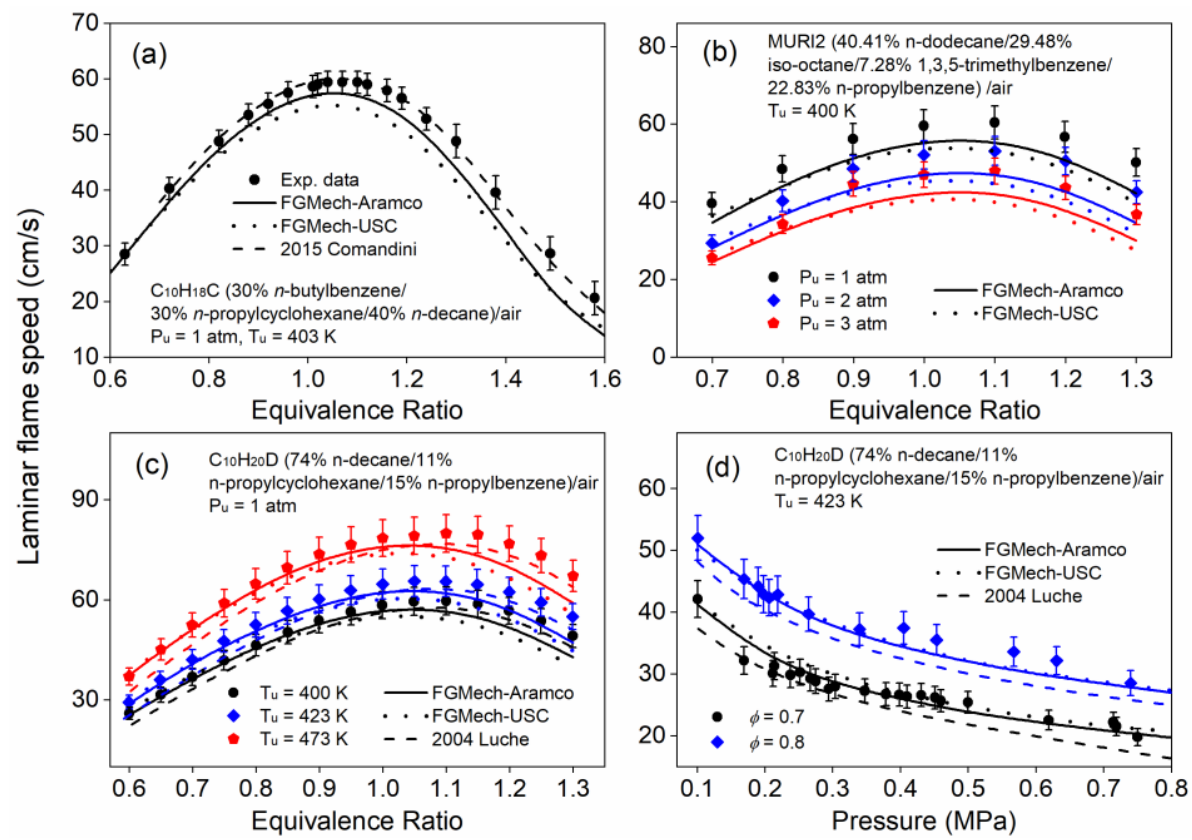

Fig. 10. Comparison of measured (symbols) and predicted (lines) laminar flame speeds for (a) Comandini surrogate $\left(\mathrm{C}_{10} \mathrm{H}_{18} \mathrm{C}\right) /$ air mixtures at $\mathrm{T}_{\mathrm{u}}=403 \mathrm{~K}$ and $\mathrm{P}_{\mathrm{u}}=1 \mathrm{~atm}$ [52], (b) MURI2 surrogate/air mixtures at $\mathrm{T}_{\mathrm{u}}=400 \mathrm{~K}$ and $\mathrm{P}_{\mathrm{u}}=1,2$ and 3 atm [76], (c) Dagaut surrogate $\left(\mathrm{C}_{10} \mathrm{H}_{20} \mathrm{D}\right) /$ air mixtures at $\mathrm{T}_{\mathrm{u}}=400,423$ and $473 \mathrm{~K}$ and $\mathrm{P}_{\mathrm{u}}=1$ atm [73] and (d) Dagaut surrogate $\left(\mathrm{C}_{10} \mathrm{H}_{20} \mathrm{D}\right) /$ air mixtures at $\phi=0.7-0.8$ and $\mathrm{T}_{\mathrm{u}}=423 \mathrm{~K}$ [73]. Solid, dotted and 
dashed lines represent predicted results of FGMech-Aramco, FGMech-USC and previous detailed (i.e. Luche [83] and Comandini [52]) models, respectively.

\subsection{Validation against experimental targets of real fuels}

Based on the FGMech approach, kinetic models were also developed for six gasoline fuels (i.e. FACE A, C, F, G, I, J), four jet fuels (i.e. Jet POSF 10264, Jet POSF 10325, Jet POSF 4658), a rocket fuel (i.e. RP POSF 5433), and an alternative aviation fuel (S-8 POSF 4734). The structure characterization of these real fuels can be found in the literature [14,30-32]. The FGMech real fuel models were then validated against the experimental data in the literature, as shown in Table 1.

\subsubsection{Real gasoline fuels}

The ignition delay times of various FACE gasolines were measured in the literature $[33,77,78]$. In this work, their data obtained at high temperatures was selected to validate the present modeling approach. Figure 11 and S8 in the Supplementary Material present comparison between the measured and predicted ignition delay times of six FACE gasolines in a high pressure shock tube at 20 and 40 atm. The FGMech-Aramco model (solid lines) predicts shorter ignition delay times at higher pressures and lower temperatures, but longer ignition delay times under lower pressure and higher temperature conditions, than the FGMech-USC. These differences are attributed solely to the different base mechanisms, since the lumped FGMech is the same. At higher pressures and lower temperatures, $\mathrm{HO}_{2-}$ related reactions play a significant role, while at lower pressures and higher temperatures, $\mathrm{OH}-\mathrm{related}$ reactions become more important. Different controlling reactions under different conditions may result in opposite performance trends of the two FGMech models. The validation results of the laminar flame speeds of FACE C/air at various pressures are presented in Fig. S9 in the Supplementary Material. Both FGMech models well predict the flame propagation of FACE C at fuel-lean and stoichiometric conditions, while the FGMech-Aramco model predictions are better under fuel-rich conditions. 


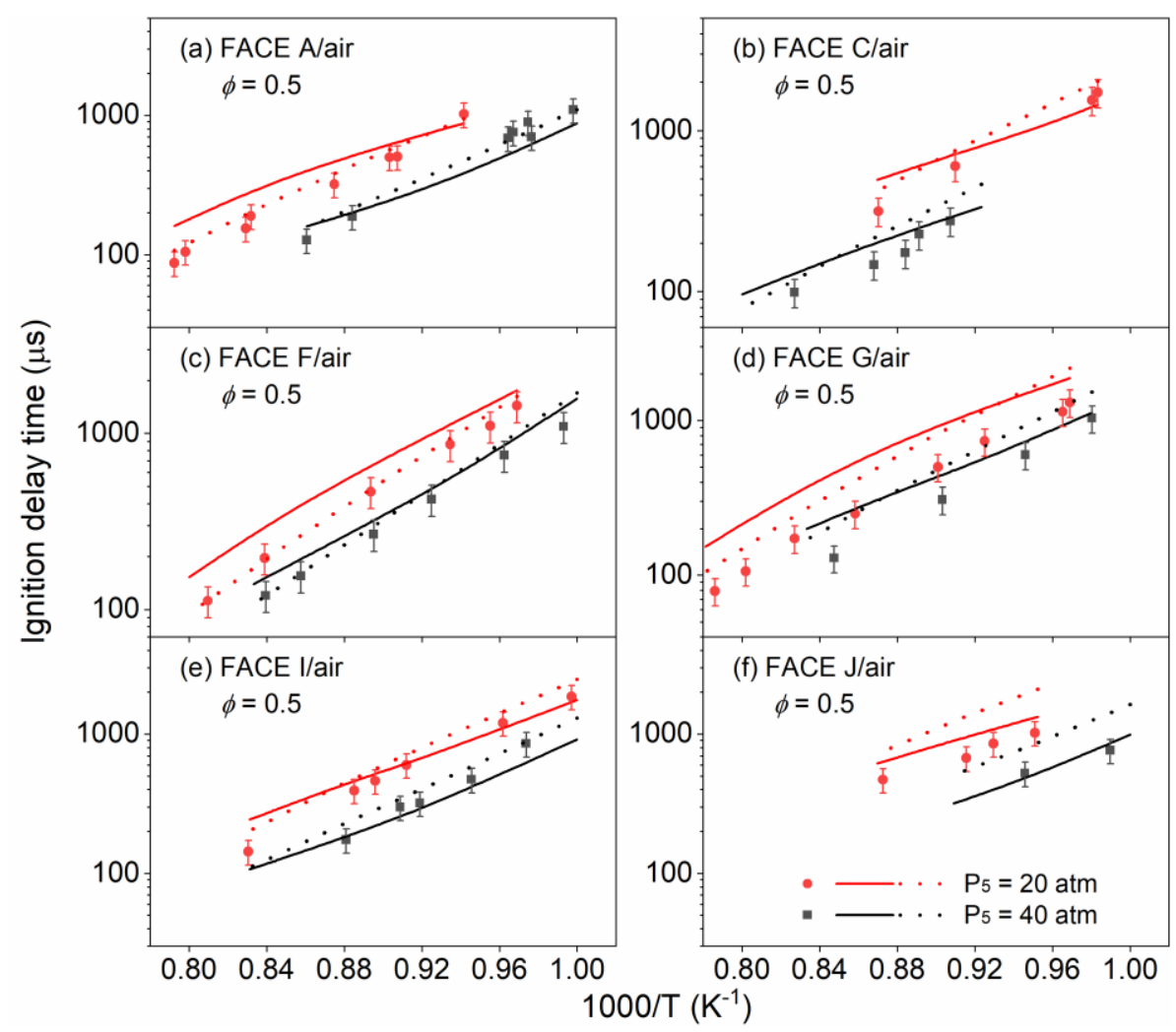

Fig. 11. Comparison of measured (symbols) and predicted (lines) ignition delay times for (a) FACE A/air [33], (b) FACE C/air [33], (c) FACE F/air [77], (d) FACE G/air [77], (e) FACE I/air [78] and (f) FACE J/air mixture [78] at $\phi=0.5$ and $\mathrm{P}_{5}=20$ and 40 atm. Solid and dotted lines represent predicted results of FGMech-Aramco and FGMech-USC, respectively.

\subsubsection{Real jet fuels}

Followings are the validation results of the FGMech models against real jet fuels. Xu et al. [24] developed real fuel models for several jet and rocket fuels based on the HyChem approach; their predicted results are included for comparison. Figure 12 presents the performance of the FGMech and HyChem models against the mole fractions of $\mathrm{CH}_{4}$ and $\mathrm{C}_{2} \mathrm{H}_{4}$, measured in the shock tube pyrolysis of Jet POSF 10264, Jet POSF 10325, Jet POSF 10289 and RP POSF 5433 at around 12 atm and $1200 \mathrm{~K}$ [24]. Considering the experimental uncertainties, both FGMechs (solid and dotted lines) displayed predictability comparable to the HyChem model. More validation results against the speciation data of Jet POSF 10325 measured in a flow reactor can be found in Fig. S10 in the Supplementary Material. 
The HyChem model predicts fuel consumption better, while the FGMech models predict the yield of $\mathrm{IC}_{4} \mathrm{H}_{8}$ better. For other intermediates, the FGMech models perform comparably to the HyChem model. Other validation results against speciation data of Jet POSF 4658, measured in a shock tube under lean and rich conditions, can be found in Figs. S11 and S12 in the Supplementary Material, respectively. In general, both FGMech models reasonably capture the mole fraction profiles of the measured intermediates.

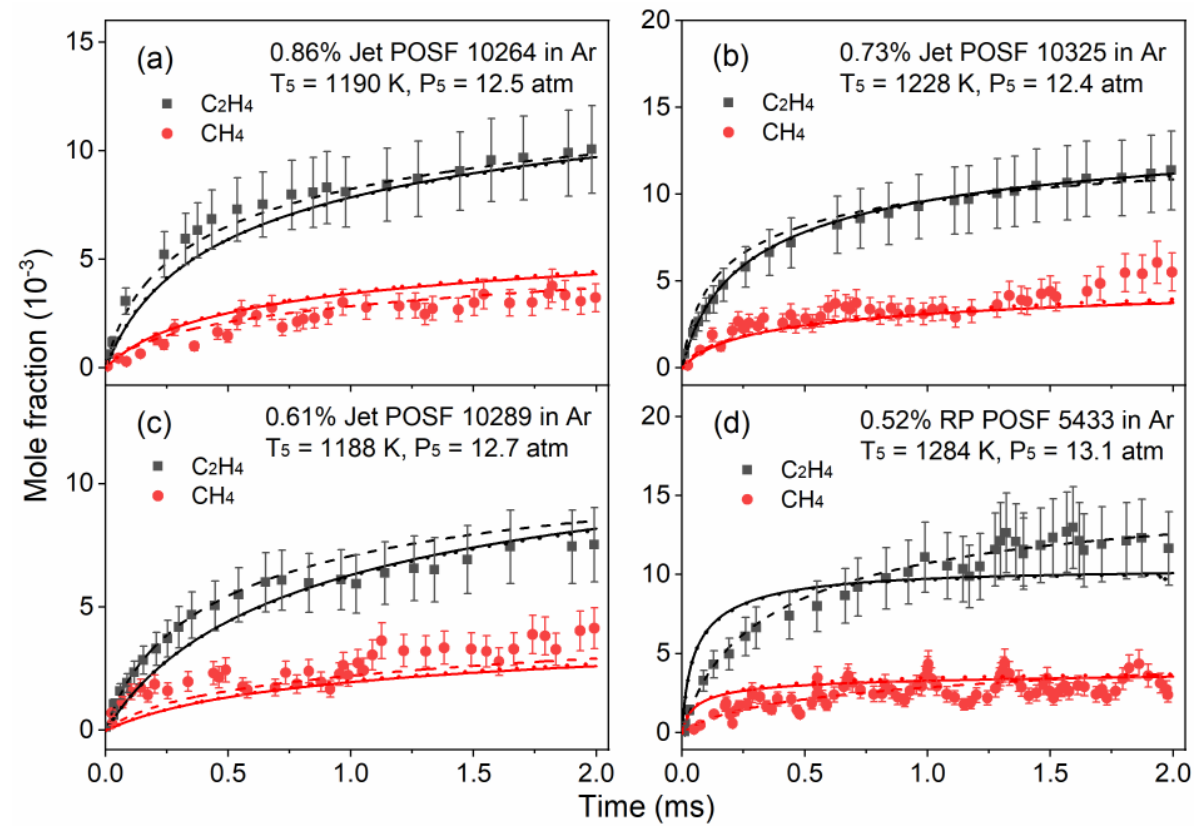

Fig. 12. Comparison of measured (symbols) [24] and predicted (lines) mole fractions of $\mathrm{CH}_{4}$ and $\mathrm{C}_{2} \mathrm{H}_{4}$ in shock tube pyrolysis of (a) Jet POSF 10264, (b) Jet POSF 10325, (c) Jet POSF 10289 and (d) RP POSF 5433. Solid, dotted, and dashed lines represent predicted results of FGMech-Aramco, FGMech-USC and HyChem model [24], respectively.

In addition to speciation data, the FGMech models for Jet POSF 10264, Jet POSF 10325, Jet POSF 10289, Jet POSF 4658, RP POSF 5433 and S-8 POSF 4734 were also validated against the global combustion parameters. Figure 13 presents the performance of FGMech and HyChem models against ignition delay times of three jet fuels under various conditions. Considering the experimental uncertainties, FGMech-USC better reproduces the measured results than FGMech-Aramco, especially 
at higher temperatures, and is comparable with the performance of the HyChem model. The FGMechAramco model overpredicts the measured ignition delay times, especially at lower temperatures. Since the base chemistry mechanism is the same between the present FGMech-USC and the HyChem models, the discrepancies of model performances between these two models originate from the differences of real-fuel sub-mechanisms. Compared with the HyChem models, the present FGMech-USC predicts a lesser ignition, especially at lower temperatures. Nevertheless, the present FGMech-USC model could still reasonably predict the experimental data. The present FGMech-Aramco and FGMech-USC models have the same sub-mechanisms for the real fuels. Therefore, compared with the FGMech-USC model, the longer ignition delay times predicted by the FGMech-Aramco model can be attributed to differences in the base chemistry mechanism. The USC base mechanism predicts a faster oxidation rate than that of Aramco mechanism at temperatures above $\sim 1200 \mathrm{~K}$, which is consistent with the validation results of other fuels, e.g. as shown in Fig. 8 for MURI2 oxidation in a shock tube.

Figures 14(a-d) compare the performance of the FGMech and HyChem models against laminar flame speeds of Jet POSF 10264, Jet POSF 10325, Jet POSF 10289 and RP POSF 5433 at $\mathrm{T}_{\mathrm{u}}=400 \mathrm{~K}$ and $\mathrm{P}_{\mathrm{u}}=1 \mathrm{~atm}$. All the models capture the experimental data reasonably well. Since Xu et al. [24] did not report real fuel models for Jet POSF 4658 and S-8 POSF 4734, only the predicted results of the present FGMech models are plotted in Figs. 14(e, f). Both FGmech models well predict these flame speed data at $\mathrm{T}_{\mathrm{u}}=400 \mathrm{~K}$ and $\mathrm{P}_{\mathrm{u}}=1-3 \mathrm{~atm}$. Under fuel-rich conditions, the FGMech-Aramco performs better, compared to the FGMech-USC. Additional validation results against the laminar flame speeds measured at various unburned temperatures can be found in Fig. S13 in the Supplementary Material. Similar model performance is observed. 

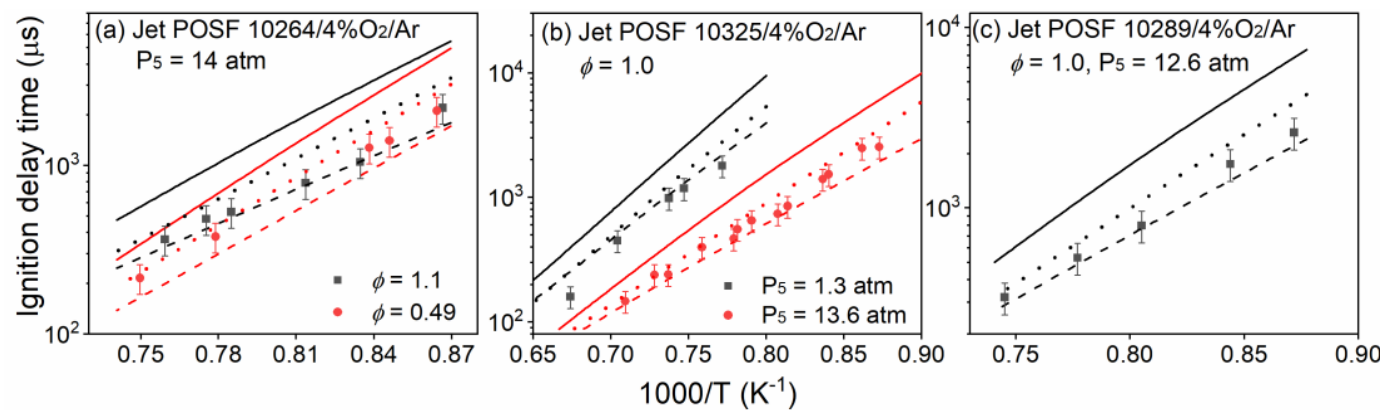

Fig. 13. Comparison of measured (symbols) and predicted (lines) ignition delay times of (a) Jet POSF $10264 / \mathrm{O}_{2} / \mathrm{Ar}$ at $\phi=0.49$ and 1.1 and $\mathrm{P}_{5}=14$ atm [79], (b) Jet POSF $10325 / \mathrm{O}_{2} / \mathrm{Ar}$ at $\phi=1.0$ and $\mathrm{P}_{5}=1.3$ and 13.6 atm [79] and (c) Jet POSF $10289 / \mathrm{O}_{2} / \mathrm{Ar}$ at $\phi=1.0$ and $\mathrm{P}_{5}=$ $12.6 \mathrm{~atm}$ in a shock tube [79]. Solid, dotted, and dashed lines represent predicted results of FGMech-Aramco, FGMech-USC and HyChem model [24], respectively.

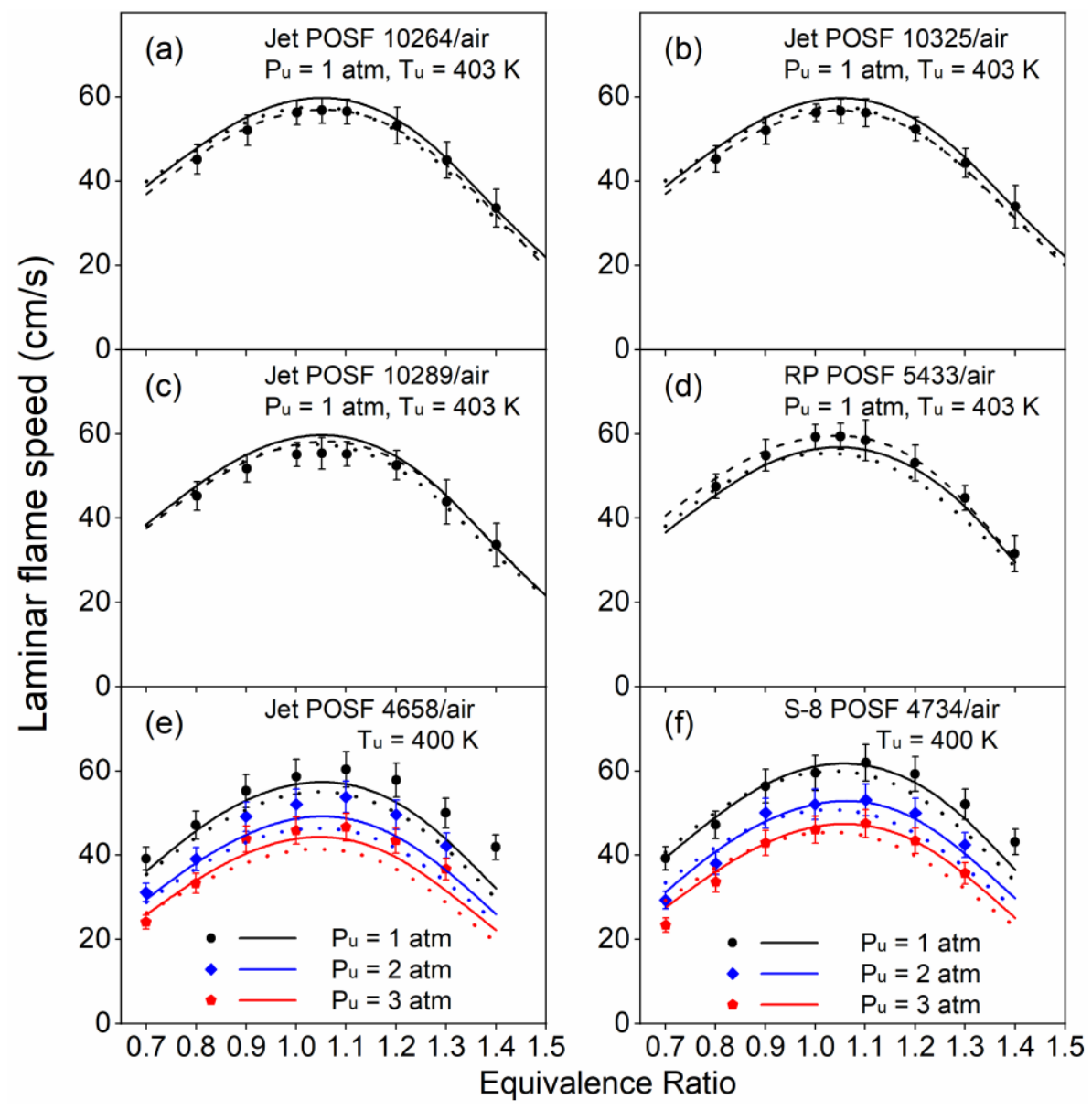

Fig. 14. Comparison of measured (symbols) and predicted (lines) laminar flame speeds of (a) Jet POSF 10264/air at $T_{u}=403 \mathrm{~K}$ and $P_{u}=1$ atm [24], (b) Jet POSF 10325/air at $T_{u}=403 \mathrm{~K}$ 
and $\mathrm{P}_{\mathrm{u}}=1 \mathrm{~atm}$ [24], (c) Jet POSF 10289/air at $\mathrm{T}_{\mathrm{u}}=403 \mathrm{~K}$ and $\mathrm{P}_{\mathrm{u}}=1 \mathrm{~atm}$ [24], (d) RP POSF 5433/air at $\mathrm{T}_{\mathrm{u}}=403 \mathrm{~K}$ and $\mathrm{P}_{\mathrm{u}}=1$ atm [24], (e) Jet POSF 4658/air at $\mathrm{T}_{\mathrm{u}}=400 \mathrm{~K}$ and $\mathrm{P}_{\mathrm{u}}=1-3 \mathrm{~atm}[76]$ and (f) S-8 POSF 4734/air at $\mathrm{T}_{\mathrm{u}}=400 \mathrm{~K}$ and $\mathrm{P}_{\mathrm{u}}=1-3 \mathrm{~atm}$ [76]. Solid, dotted and dashed lines represent predicted results of FGMech-Aramco, FGMech-USC and HyChem model [24], respectively.

\section{Discussion}

Functional group distributions accurately describe the chemical nature of fuel mixtures and can be used to account for real fuel variability. The pool of intermediate species governs critical combustion properties. The present FGMech approach directly connects the distribution of functional groups with the distribution of intermediate species generated during fuel (oxidative) pyrolysis. This section focuses on the relationship between functional groups and intermediate species pools predicted by the FGMech-Aramco model.

\subsection{Relationship between functional groups and intermediate pools: Jet fuel and its surrogates}

Figure 15a presents the weight percent of different functional groups in the Comandini [52], MURI2 [51], Dagaut [8], and Aachen [50] surrogate jet fuels, as well as Jet POSF10264. Although the weight percent of each functional group is slightly different in the various fuels, the dominant functional group is paraffinic $\mathrm{CH}_{2}$, which is around two times higher than the second most abundant paraffinic $\mathrm{CH}_{3}$ group (see bars in Fig. 15a). The relative weight of each functional group was calculated by normalizing against the weight percent of paraffinic $\mathrm{CH}_{2}$ (see lines and symbols in Fig. 15a); similar trends were found in the relative weights across different fuels. 


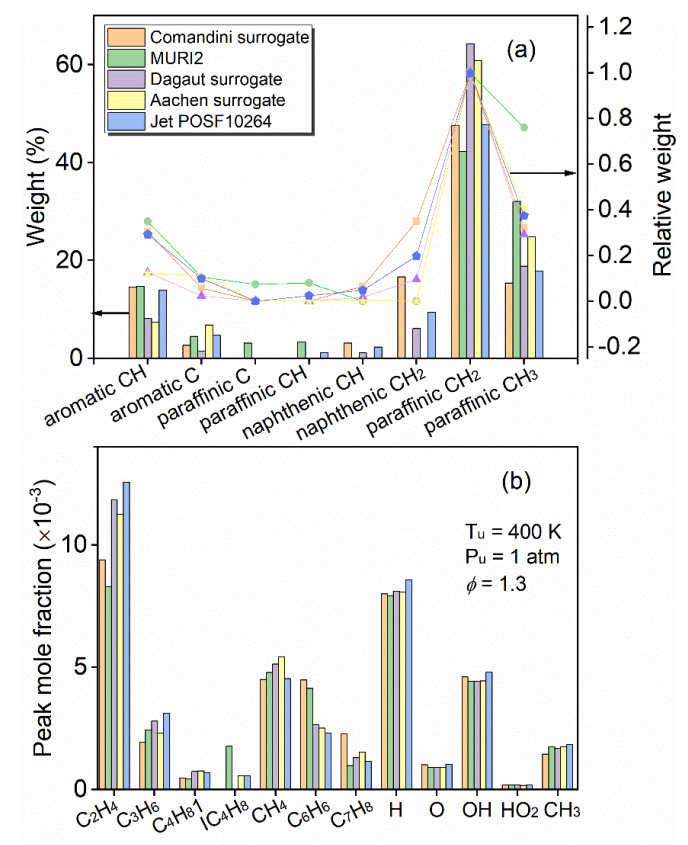

Fig. 15. (a) Functional group comparison among different jet fuel surrogates and POSF 10264. Formulation of different jet fuel surrogates noted in Fig. 3 caption; (b) intermediate distributions predicted by FGMech-Aramco model in the flame propagation of jet surrogates and POSF 10264 at $\mathrm{T}_{\mathrm{u}}=400 \mathrm{~K}, \mathrm{P}_{\mathrm{u}}=1 \mathrm{~atm}$ and $\phi=1.3$.

Figure $15 \mathrm{~b}$ presents the predicted peak mole fractions of key intermediate species in the above fuel/air flames at $\mathrm{T}_{\mathrm{u}}=400 \mathrm{~K}, \mathrm{P}_{\mathrm{u}}=1 \mathrm{~atm}$ and $\phi=1.3$ by FGMech-Aramco. In general, the peak mole fractions for different stable species and radicals are very close, which is consistent with the similar measured and predicted laminar flame speeds of these fuels under this condition. As shown in Fig. 15b, $\mathrm{C}_{2} \mathrm{H}_{4}$ is dominant among all the stable species, which corresponds to the paraffinic $\mathrm{CH}_{2}$ group being the most abundant in these fuels (see Fig. 15a). Fuel radicals with a structure of $\mathrm{R}-\mathrm{CH}_{2}-\mathrm{CH}_{2} \cdot \operatorname{directly}$ produce $\mathrm{C}_{2} \mathrm{H}_{4}$ via $\beta$-scission reactions; more paraffinic $\mathrm{CH}_{2}$ groups in real fuel mixtures contribute to more $\mathrm{R}-\mathrm{CH}_{2}-\mathrm{CH}_{2}$ structures, producing more $\mathrm{C}_{2} \mathrm{H}_{4} \cdot \mathrm{CH}_{4}$ is the second-most abundant stable intermediate in Fig. 15b, which corresponds to the paraffinic $\mathrm{CH}_{3}$ group being the second most abundant group, as shown in Fig. 15a. The yield of $\mathrm{CH}_{4}$ is directly related to the yield of the methyl radical since $\mathrm{CH}_{4}$ is produced mainly by $\mathrm{H}$-atom abstraction reactions by methyl radical. More 
paraffinic $\mathrm{CH}_{3}$ groups in real fuel mixtures provide more opportunity to produce methyl radical upon pyrolysis, and subsequently to generate more $\mathrm{CH}_{4}$. Therefore, the paraffinic $\mathrm{CH}_{2}$ and $\mathrm{CH}_{3}$ group in real fuel mixtures are strongly correlated with the yield of $\mathrm{C}_{2} \mathrm{H}_{4}$ and $\mathrm{CH}_{4}$, respectively. The yield of $\mathrm{C}_{2} \mathrm{H}_{4}$ is around two times greater than that of $\mathrm{CH}_{4}$ (see Fig. 15b), while the weight percent of paraffinic $\mathrm{CH}_{2}$ is also around 2 times higher than that of paraffinic $\mathrm{CH}_{3}$ (see Fig. 15a), suggesting that the relative yield between $\mathrm{C}_{2} \mathrm{H}_{4}$ and $\mathrm{CH}_{4}$ can be attributed to the relative weight between paraffinic $\mathrm{CH}_{2}$ and $\mathrm{CH}_{3}$.

\subsection{Relationship between functional groups and intermediate pools: Gasoline and jet fuels}

This section focuses on variations in the intermediate pools of different fuels and the relationship to their functional groups. Jet POSF10264 and FACE J were selected as the representative jet and gasoline fuels, respectively. Their functional group distributions are found in Fig. 16a. As mentioned above, in Jet POSF10264, paraffinic $\mathrm{CH}_{2}$ is the dominant functional group; its weight percent is around two times higher than paraffinic $\mathrm{CH}_{3}$ (green bars in Fig. 16a). In contrast, the dominant functional groups in FACE J are both paraffinic $\mathrm{CH}_{2}$ and paraffinic $\mathrm{CH}_{3}$, and the weight percent of paraffinic $\mathrm{CH}_{3}$ is slightly higher than that of paraffinic $\mathrm{CH}_{2}$ (orange bars in Fig. 16a). The relative weight of each functional group in the two real fuels was also calculated by normalizing against the weight percent of paraffinic $\mathrm{CH}_{2}$ in Jet POSF10264 and that of paraffinic $\mathrm{CH}_{3}$ in FACE J, as seen from the lines and symbols in Fig. 16a. The trends of the relative weight between Jet POSF10264 and FACE J are quite different, resulting mainly from the relative weight between paraffinic $\mathrm{CH}_{2}$ and paraffinic $\mathrm{CH}_{3}$. 


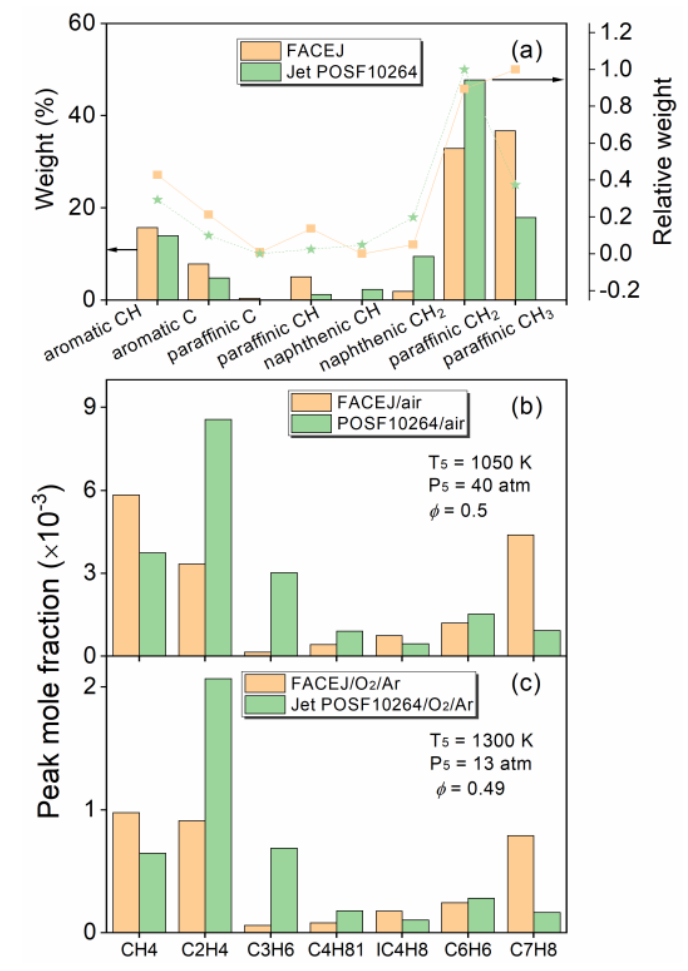

Fig. 16. (a) Functional group comparison between FACE J and Jet POSF10264; Intermediate distributions in ignition of FACE $\mathrm{J}$ and Jet POSF10264 at (b) $\mathrm{T}_{5}=1050 \mathrm{~K}, \mathrm{P}_{\mathrm{u}}=40 \mathrm{~atm}$ and $\phi=0.5$ and (c) $\mathrm{T}_{5}=1400 \mathrm{~K}, \mathrm{P}_{5}=13 \mathrm{~atm}$ and $\phi=0.49$.

Figures $16(\mathrm{~b}, \mathrm{c})$ present peak mole fractions of critical intermediates generated in Jet POSF10264 and FACE J under two different ignition conditions from the predictions of FGMechAramco. At different temperature and pressures, $\mathrm{C}_{2} \mathrm{H}_{4}$ dominates the intermediate pool in the ignition of Jet POSF10264, while $\mathrm{C}_{2} \mathrm{H}_{4}, \mathrm{CH}_{4}$ and $\mathrm{C}_{7} \mathrm{H}_{8}$ are all major intermediates in the ignition of FACE J. For Jet POSF10264, the peak mole fractions of $\mathrm{C}_{2} \mathrm{H}_{4}$ and $\mathrm{CH}_{4}$ are notably different, which corresponds to significant differences in the weight percent between paraffinic $\mathrm{CH}_{3}$ and paraffinic $\mathrm{CH}_{2}$ group (Fig. 16a). In FACE $\mathrm{J}$, the small discrepancies between the peak mole fractions of $\mathrm{C}_{2} \mathrm{H}_{4}$ and $\mathrm{CH}_{4}$ are consistent with the minor differences in the weight percent between the paraffinic $\mathrm{CH}_{3}$ and paraffinic $\mathrm{CH}_{2}$ group in the FACE $\mathrm{J}$ mixture. The case of FACE $\mathrm{J}$ also confirms the close relationship between paraffinic $\mathrm{CH}_{2}$ and the yield of $\mathrm{C}_{2} \mathrm{H}_{4}$, as well as the connection between paraffinic $\mathrm{CH}_{3}$ and $\mathrm{CH}_{4}$.

In summary, for different jet fuel surrogates and their respective real fuel, the dominant 
functional groups are the same. As a result, the intermediate distributions - including both stable species and radicals - are similar. While for FACE J and Jet POSF10264, the dominant functional groups are different, corresponding to large differences in the distributions of critical intermediates. The yields of $\mathrm{C}_{2} \mathrm{H}_{4}$ and $\mathrm{CH}_{4}$ in the intermediate pools are also found to be significantly impacted by the paraffinic $\mathrm{CH}_{2}$ and $\mathrm{CH}_{3}$ group in fuel mixtures, respectively. The relative weight percent between paraffinic $\mathrm{CH}_{2}$ and $\mathrm{CH}_{3}$ may relate to the relative yield between $\mathrm{C}_{2} \mathrm{H}_{4}$ and $\mathrm{CH}_{4}$.

\section{Conclusions and perspectives}

In combination with the companion paper from this group [25], this work proposed a functional group-based approach for modeling high-temperature combustion of surrogate mixtures and real fuels. The formulation of lumped reaction steps followed that proposed in the HyChem approach, while the thermodynamic and transport data of fuels, stoichiometric parameters, and the rate constants of the lumped reactions were derived from functional group distributions in the fuel mixtures. Stoichiometric parameters were predicted by the MLR model developed in the companion paper; the thermodynamic data of the fuels were estimated based on Benson group additivity by adding the contributions of each functional group. The kinetic rate constants of the lumped reactions were obtained from rate rules developed for pure fuels, and critical transport data, i.e., $\mathrm{LJ}$ parameters were correlated with $\mathrm{T}_{\mathrm{b}}, \mathrm{T}_{\mathrm{c}}$ and $\mathrm{P}_{\mathrm{c}}$, which were estimated based on the Joback method. Unlike the HyChem approach, the stoichiometric parameters and rate constants of the lumped reactions in the FGMech did not rely on being fitted to real fuel experimental data, and the thermodynamic and transport data of the fuel mixtures were free from the formulation of surrogate fuels and analogy with $n$-alkanes, respectively. In this work, 14 surrogate and 12 real-fuel models were constructed based on the FGMech approach; they were then validated against experimental data in the literature. The FGMechs reasonably capture the experimental data in the literature, indicating that the present model approach could serve as an 
alternate to modeling the combustion behaviors of multiple fuel mixtures. Based on the FGMechAramco, it was found that the yields of $\mathrm{C}_{2} \mathrm{H}_{4}$ and $\mathrm{CH}_{4}$ under both ignition and flame conditions were closely related to the weight percent of paraffinic $\mathrm{CH}_{2}$ and $\mathrm{CH}_{3}$ group, respectively.

Further efforts will focus on improving the FGMech performance. Firstly, the formulation of present FGMech can be changed. For example, $\mathrm{C}_{6} \mathrm{H}_{6}$ and $\mathrm{C}_{7} \mathrm{H}_{8}$ in $\mathrm{R} 1-\mathrm{R} 7$ mainly serve as key secondary pyrolysis products in many fuels, which can be replaced by phenyl and benzyl radicals, respectively, since these two radicals are the primary products in aromatic pyrolysis (especially for alkylbenzenes); their yields can be trained on the stoichiometries from a lumped mechanism. In this way, the formation temperature windows of $\mathrm{C}_{6} \mathrm{H}_{6}$ and $\mathrm{C}_{7} \mathrm{H}_{8}$ can be higher, and consistent with those of the secondary products. Second, the group additivity method adopted in this work does not correct for non-ideal interactions in fuel mixtures. Neglecting interaction between non-neighboring groups and unknown symmetry numbers of real fuels introduce another source of uncertainties in the current approach, which may lead to larger influences on predictions at low- and intermediate temperatures [84]. More accurate thermodynamic data can be obtained by data-based research, i.e., correlating the functional groups directly with enthalpy, entropy and heat capacity [85]. Finally, discrepancies between the FGMech-Aramco and the FGMech-USC highlight the significance of an accurate base mechanism, which requires not only an accurate $\mathrm{C}_{0}-\mathrm{C}_{4}$ mechanism, but also a reliable mechanism for $\mathrm{C}_{6} \mathrm{H}_{6}$ and $\mathrm{C}_{7} \mathrm{H}_{8}$. Plans for the future include extension of the current FGMech framework to model low-temperature combustion chemistry, quantifying the model uncertainties and providing smaller reduced/skeletal models for high-fidelity CFD simulations.

\section{Acknowledgements}

This work was supported by King Abdullah University of Science and Technology (KAUST) with funds allocated to the Clean Combustion Research Center. Contributions from the KAUST Clean Fuels 
Consortium (KCFC), and its member companies are gratefully acknowledged.

\section{References}

[1] F.L. Dryer, Chemical kinetic and combustion characteristics of transportation fuels, Proc. Combust. Inst. 35 (2015) 117-144.

[2] R.D. Reitz, G. Duraisamy, Review of high efficiency and clean reactivity controlled compression ignition (RCCI) combustion in internal combustion engines, Prog. Energy Combust. Sci. 46 (2015) 12-71.

[3] G.T. Kalghatgi, Developments in internal combustion engines and implications for combustion science and future transport fuels, Proc. Combust. Inst. 35 (2015) 101-115.

[4] R.D. Reitz, Directions in internal combustion engine research, Combust. Flame 160 (2013) 1-8.

[5] Z. Luo, S. Som, S.M. Sarathy, M. Plomer, W.J. Pitz, D.E. Longman, T. Lu, Development and validation of an $n$ dodecane skeletal mechanism for spray combustion applications, Combust. Theory Modell. 18 (2014) 187-203.

[6] G.E. Bogin, E. Osecky, J.Y. Chen, M.A. Ratcliff, J. Luecke, B.T. Zigler, A.M. Dean, Experiments and computational fluid dynamics modeling analysis of large $n$-Alkane ignition kinetics in the ignition quality tester, Energy Fuels 28 (2014) 4781-4794.

[7] S. Dooley, S.H. Won, S. Jahangirian, Y. Ju, F.L. Dryer, H. Wang, M.A. Oehlschlaeger, The combustion kinetics of a synthetic paraffinic jet aviation fuel and a fundamentally formulated, experimentally validated surrogate fuel, Combust. Flame 159 (2012) 3014-3020.

[8] P. Dagaut, A. El Bakali, A. Ristori, The combustion of kerosene: Experimental results and kinetic modelling using 1to 3-component surrogate model fuels, Fuel 85 (2006) 944-956.

[9] A. Violi, S. Yan, E.G. Eddings, A.F. Sarofim, S. Granata, T. Faravelli, E. Ranzi, Experimental formulation and kinetic model for JP-8 surrogate mixtures, Combust. Sci. Technol. 174 (2002) 399-417.

[10] T. Edwards, L.Q. Maurice, Surrogate Mixtures to Represent Complex Aviation and Rocket Fuels, J. Propul. Power 17 (2001) 461-466.

[11] S.M. Sarathy, A. Farooq, G.T. Kalghatgi, Recent progress in gasoline surrogate fuels, Prog. Energy Combust. Sci. 65 (2018) 67-108.

[12] W.J. Pitz, C.J. Mueller, Recent progress in the development of diesel surrogate fuels, Prog. Energy Combust. Sci. 37 (2011) 330-350.

[13] J. Yu, Y. Ju, X. Gou, Surrogate fuel formulation for oxygenated and hydrocarbon fuels by using the molecular structures and functional groups, Fuel 166 (2016) 211-218.

[14] A.G. Abdul Jameel, N. Naser, G. Issayev, J. Touitou, M.K. Ghosh, A.-H. Emwas, A. Farooq, S. Dooley, S.M. Sarathy, A minimalist functional group (MFG) approach for surrogate fuel formulation, Combust. Flame 192 (2018) 250-271.

[15] E. Ranzi, A. Frassoldati, A. Stagni, M. Pelucchi, A. Cuoci, T. Fravelli, Reduced Kinetic Schemes of Complex Reaction Systems: Fossil and Biomass-Derived Transportation Fuels, Int. J. Chem. Kinet. 46 (2014) 512-542.

[16] E. Ranzi, M. Dente, A. Goldaniga, G. Bozzano, T. Faravelli, Lumping procedures in detailed kinetic modeling of gasification, pyrolysis, partial oxidation and combustion of hydrocarbon mixtures, Prog. Energy Combust. Sci. 27 (2001) 99-139.

[17] E. Ranzi, G. Biardi, M. Dente, S. Plerucci, Initial product distributions from pyrolysis of normal and branched paraffins, Ind. Eng. Chem. Fundam. 22 (1983) 132-139.

[18] E. Ranzi, A. Frassoldati, S. Granata, T. Faravelli, Wide-range kinetic modeling study of the pyrolysis, partial oxidation, and combustion of heavy n-alkanes, Industrial \& Engineering Chemistry Research 44 (2005) 5170-5183.

[19] S.B. Jaffe, H. Freund, W.N. Olmstead, Extension of Structure-Oriented Lumping to Vacuum Residua, Ind. Eng. Chem. Res. 44 (2005) 9840-9852.

[20] R.J. Quann, S.B. Jaffe, Structure-oriented lumping: describing the chemistry of complex hydrocarbon mixtures, Ind. Eng. Chem. Res. 31 (1992) 2483-2497. 
[21] M. Mehl, W.J. Pitz, S.M. Sarathy, C.K. Westbrook, Modeling the combustion of high molecular weight fuels by a functional group approach, Int. J. Chem. Kinet. 44 (2012) 257-276.

[22] K. Han, W.H. Green, A Fragment-Based Mechanistic Kinetic Modeling Framework for Complex Systems, Ind. Eng. Chem. Res. 57 (2018) 14022-14030.

[23] H. Wang, R. Xu, K. Wang, C.T. Bowman, R.K. Hanson, D.F. Davidson, K. Brezinsky, F.N. Egolfopoulos, A physicsbased approach to modeling real-fuel combustion chemistry - I. Evidence from experiments, and thermodynamic, chemical kinetic and statistical considerations, Combust. Flame 193 (2018) 502-519.

[24] R. Xu, K. Wang, S. Banerjee, J. Shao, T. Parise, Y. Zhu, S. Wang, A. Movaghar, D.J. Lee, R. Zhao, X. Han, Y. Gao, T. Lu, K. Brezinsky, F.N. Egolfopoulos, D.F. Davidson, R.K. Hanson, C.T. Bowman, H. Wang, A physics-based approach to modeling real-fuel combustion chemistry - II. Reaction kinetic models of jet and rocket fuels, Combust. Flame 193 (2018) 520-537.

[25] X. Zhang, K.K. Yalamanchi, S.M. Sarathy, A functional-group-based approach to modeling real-fuel combustion chemistry - I: FGMech prediction of stoichiometric parameters for lumped pyrolysis reactions, Combust. Flame, (2020) submitted.

[26] X. Zhang, S.M. Sarathy, A lumped kinetic model for high-temperature pyrolysis and combustion of 50 surrogate fuel components and their mixtures, Fuel 286 (2021) 119361.

[27] Y. Li, C.-W. Zhou, K.P. Somers, K. Zhang, H.J. Curran, The oxidation of 2-butene: A high pressure ignition delay, kinetic modeling study and reactivity comparison with isobutene and 1-butene, Proc. Combust. Inst. 36 (2017) $403-411$.

[28] H. Wang, X. You, A.V. Joshi, S.G. Davis, A. Laskin, F. Egolfopoulos, C.K. Law, USC Mech Version II. Hightemperature combustion reaction model of $\mathrm{H}_{2} / \mathrm{CO} / \mathrm{C}_{1}-\mathrm{C}_{4}$ compounds. http://ignis.usc.edu/USC_Mech_II.htm, (2007).

[29] K.G. Joback, R.C. Reid, Estimation of pure-component properties from group-contributions, Chem. Eng. Commun. 57 (1987) 233-243.

[30] T.M. Lovestead, J.L. Burger, N. Schneider, T.J. Bruno, Comprehensive assessment of composition and thermochemical variability by high resolution GC/QToF-MS and the advanced distillation-curve method as a basis of comparison for reference fuel development, Energy Fuels 30 (2016) 10029-10044.

[31] M.L. Huber, B.L. Smith, L.S. Ott, T.J. Bruno, Surrogate mixture model for the thermophysical properties of synthetic aviation fuel S-8: Explicit application of the advanced distillation curve, Energy Fuels 22 (2008) 1104-1114.

[32] T.M. Lovestead, B.C. Windom, J.R. Riggs, C. Nickell, T.J. Bruno, Assessment of the compositional variability of RP1 and RP-2 with the advanced distillation curve approach, Energy Fuels 24 (2010) 5611-5623.

[33] S.M. Sarathy, G. Kukkadapu, M. Mehl, W. Wang, T. Javed, S. Park, M.A. Oehlschlaeger, A. Farooq, W.J. Pitz, C.-J. Sung, Ignition of alkane-rich FACE gasoline fuels and their surrogate mixtures, Proc. Combust. Inst. 35 (2015) 249-257.

[34] ASTM D6733: Individual components in spark ignition fuels by capillary high resolution GC.

[35] ASTM D6730: Individual components in spark ignition fuels by (pre-column) high resolution GC.

[36] ASTM D6729: Individual components in spark ignition fuels by high resolution GC.

[37] ASTM D5134: Detailed analysis of petroleum naphthas through n-Nonane by gas chromatography (GC).

[38] K. Wang, C.T. Bowman, H. Wang, Kinetic analysis of distinct product generation in oxidative pyrolysis of four octane isomers, Proc. Combust. Inst. 37 (2019) 531-538.

[39] C.K. Westbrook, W.J. Pitz, O. Herbinet, H.J. Curran, E.J. Silke, A comprehensive detailed chemical kinetic reaction mechanism for combustion of n-alkane hydrocarbons from n-octane to n-hexadecane, Combust. Flame 156 (2009) 181199.

[40] H.J. Curran, P. Gaffuri, W.J. Pitz, C.K. Westbrook, A comprehensive modeling study of iso-octane oxidation, Combust. Flame 129 (2002) 253-280.

[41] S.M. Sarathy, C.K. Westbrook, M. Mehl, W.J. Pitz, C. Togbe, P. Dagaut, H. Wang, M.A. Oehlschlaeger, U. Niemann, K. Seshadri, P.S. Veloo, C. Ji, F.N. Egolfopoulos, T. Lu, Comprehensive chemical kinetic modeling of the oxidation of 2methylalkanes from C7 to C20, Combust. Flame 158 (2011) 2338-2357.

[42] C.W. Gao, J.W. Allen, W.H. Green, R.H. West, Reaction Mechanism Generator: Automatic construction of chemical kinetic mechanisms, Computer Physics Communications 203 (2016) 212-225. 
[43] L. Cai, H. Pitsch, S.Y. Mohamed, V. Raman, J. Bugler, H. Curran, S.M. Sarathy, Optimized reaction mechanism rate rules for ignition of normal alkanes, Combust. Flame 173 (2016) 468-482.

[44] Z. Wang, Z. Cheng, W. Yuan, J. Cai, L. Zhang, F. Zhang, F. Qi, J. Wang, An experimental and kinetic modeling study of cyclohexane pyrolysis at low pressure, Combust. Flame 159 (2012) 2243-2253.

[45] Z. Wang, L. Ye, W. Yuan, L. Zhang, Y. Wang, Z. Cheng, F. Zhang, F. Qi, Experimental and kinetic modeling study on methylcyclohexane pyrolysis and combustion, Combust. Flame 161 (2014) 84-100.

[46] Z. Wang, L. Zhao, Y. Wang, H. Bian, L. Zhang, F. Zhang, Y. Li, S.M. Sarathy, F. Qi, Kinetics of ethylcyclohexane pyrolysis and oxidation: An experimental and detailed kinetic modeling study, Combust. Flame 162 (2015) 2873-2892.

[47] W. Yuan, Y. Li, P. Dagaut, J. Yang, F. Qi, Investigation on the pyrolysis and oxidation of toluene over a wide range conditions. I. Flow reactor pyrolysis and jet stirred reactor oxidation, Combust. Flame 162 (2015) 3-21.

[48] W. Yuan, Y. Li, G. Pengloan, C. Togbé, P. Dagaut, F. Qi, A comprehensive experimental and kinetic modeling study of ethylbenzene combustion, Combust. Flame 166 (2016) 255-265.

[49] W. Yuan, Y. Li, P. Dagaut, Y. Wang, Z. Wang, F. Qi, A comprehensive experimental and kinetic modeling study of npropylbenzene combustion, Combust. Flame 186 (2017) 178-192.

[50] S. Honnet, K. Seshadri, U. Niemann, N. Peters, A surrogate fuel for kerosene, Proc. Combust. Inst. 32 (2009) $485-$ 492.

[51] S. Dooley, S.H. Won, J. Heyne, T.I. Farouk, Y. Ju, F.L. Dryer, K. Kumar, X. Hui, C.-J. Sung, H. Wang, M.A. Oehlschlaeger, V. Iyer, S. Iyer, T.A. Litzinger, R.J. Santoro, T. Malewicki, K. Brezinsky, The experimental evaluation of a methodology for surrogate fuel formulation to emulate gas phase combustion kinetic phenomena, Combust. Flame 159 (2012) 1444-1466.

[52] A. Comandini, T. Dubois, N. Chaumeix, Laminar flame speeds of n-decane, n-butylbenzene, and n-propylcyclohexane mixtures, Proc. Combust. Inst. 35 (2015) 671-678.

[53] S.M. Burke, J.M. Simmie, H.J. Curran, Critical evaluation of thermochemical properties of $\mathrm{C}_{1}-\mathrm{C}_{4}$ species: Updated group-contributions to estimate thermochemical properties, J. Phys. Chem. Ref. Data 44 (2015) 013101.

[54] E.R. Ritter, J.W. Bozzelli, THERM: Thermodynamic property estimation for gas phase radicals and molecules, Int. J. Chem. Kinet. 23 (1991) 767-778.

[55] S.W. Benson, F.R. Cruickshank, D.M. Golden, G.R. Haugen, H.E. O'Neal, A.S. Rodgers, R. Shaw, R. Walsh, Additivity rules for the estimation of thermochemical properties, Chem. Rev. 69 (1969) 279-324.

[56] S.W. Benson, J.H. Buss, Additivity Rules for the Estimation of Molecular Properties. Thermodynamic Properties, J. Chem. Phys. 29 (1958) 546-572.

[57] A. Ahmed, M. Hantouche, M. Khurshid, S.Y. Mohamed, E.F. Nasir, A. Farooq, W.L. Roberts, O.M. Knio, S.M. Sarathy, Impact of thermodynamic properties and heat loss on ignition of transportation fuels in rapid compression machines, Fuel 218 (2018) 203-212.

[58] L.S. Tee, S. Gotoh, W.E. Stewart, Molecular Parameters for normal fluids - Lennard-Jones 12-6 potential, I\&EC Fundamentals 5 (1966) 356-363.

[59] B.I. Lee, M.G. Kesler, A generalized thermodynamic correlation based on three-parameter corresponding states, AIChE J. 21 (1975) 510-527.

[60] R. Bosque, J. Sales, Polarizabilities of Solvents from the Chemical Composition, J. Chem. Inf. Comput. Sci. 42 (2002) 1154-1163.

[61] ANSYS Chemkin-Pro: a chemical kinetics package for analysis of gas-phase chemical kinetics. Reaction Design, 2019 R2.

[62] M. Chaos, F.L. Dryer, Chemical-kinetic modeling of ignition delay: Considerations in interpreting shock tube data, Int. J. Chem. Kinet. 42 (2010) 143-150.

[63] F.L. Dryer, F.M. Haas, J. Santner, T.I. Farouk, M. Chaos, Interpreting chemical kinetics from complex reactionadvection-diffusion systems: Modeling of flow reactors and related experiments, Prog. Energy Combust. Sci. 44 (2014) 19-39.

[64] F. Karsenty, S.M. Sarathy, C. Togbé, C.K. Westbrook, G. Dayma, P. Dagaut, M. Mehl, W.J. Pitz, Experimental and 
Kinetic Modeling Study of 3-Methylheptane in a Jet-Stirred Reactor, Energy Fuels 26 (2012) 4680-4689.

[65] E. Ranzi, A. Frassoldati, R. Grana, A. Cuoci, T. Faravelli, A.P. Kelley, C.K. Law, Hierarchical and comparative kinetic modeling of laminar flame speeds of hydrocarbon and oxygenated fuels, Prog. Energy Combust. Sci. 38 (2012) 468-501.

[66] C. Shao, G. Kukkadapu, S.W. Wagnon, W.J. Pitz, S.M. Sarathy, PAH formation from jet stirred reactor pyrolysis of gasoline surrogates, Combust. Flame 219 (2020) 312-326.

[67] T. Javed, E.F. Nasir, E.-t. Es-sebbar, A. Farooq, A comparative study of the oxidation characteristics of two gasoline fuels and an n-heptane/iso-octane surrogate mixture, Fuel 140 (2015) 201-208.

[68] O. Mannaa, M.S. Mansour, W.L. Roberts, S.H. Chung, Laminar burning velocities at elevated pressures for gasoline and gasoline surrogates associated with RON, Combust. Flame 162 (2015) 2311-2321.

[69] C. Shao, H. Wang, N. Atef, Z. Wang, B. Chen, M. Almalki, Y. Zhang, C. Cao, J. Yang, S.M. Sarathy, Polycyclic aromatic hydrocarbons in pyrolysis of gasoline surrogates (n-heptane/iso-octane/toluene), Proc. Combust. Inst. 37 (2019) 993-1001.

[70] H. Li, L. Yu, S. Sun, S. Wang, X. Lu, Z. Huang, A shock tube experimental and modeling study of multicomponent gasoline surrogates diluted with exhaust gas recirculation, Energy Fuels 32 (2018) 3800-3813.

[71] A.J. Dean, O.G. Penyazkov, K.L. Sevruk, B. Varatharajan, Autoignition of surrogate fuels at elevated temperatures and pressures, Proc. Combust. Inst. 31 (2007) 2481-2488.

[72] R. Le Dortz, M. Bellenoue, L. Bonneau, E. Mazanchenko, J. Sotton, C. Strozzi, Laminar burning velocities and markstein lengths of jet fuel surrogate/air mixtures in a spherical chamber, the $8^{\text {th }}$ European Combustion Symposium, Dubrovnik, Croatia, 2017.

[73] Y. Wu, V. Modica, X. Yu, F. Grisch, Experimental investigation of laminar flame speed measurement for kerosene fuels: Jet A-1, surrogate fuel, and its pure components, Energy Fuels 32 (2018) 2332-2343.

[74] U. Steil, M. Braun-Unkhoff, M. Aigner, An experimental and modeling study on the auto ignition of kerosene and surrogate fuel mixture 46th AIAA Aerospace Sciences Meeting and Exhibit, Reno, Nevada, 2008.

[75] T. Malewicki, S. Gudiyella, K. Brezinsky, Experimental and modeling study on the oxidation of Jet A and the ndodecane/iso-octane/n-propylbenzene/1,3,5-trimethylbenzene surrogate fuel, Combust. Flame 160 (2013) 17-30.

[76] X. Hui, C.-J. Sung, Laminar flame speeds of transportation-relevant hydrocarbons and jet fuels at elevated temperatures and pressures, Fuel 109 (2013) 191-200.

[77] S.M. Sarathy, G. Kukkadapu, M. Mehl, T. Javed, A. Ahmed, N. Naser, A. Tekawade, G. Kosiba, M. AlAbbad, E. Singh, S. Park, M.A. Rashidi, S.H. Chung, W.L. Roberts, M.A. Oehlschlaeger, C.-J. Sung, A. Farooq, Compositional effects on the ignition of FACE gasolines, Combust. Flame 169 (2016) 171-193.

[78] T. Javed, A. Ahmed, L. Lovisotto, G. Issayev, J. Badra, S.M. Sarathy, A. Farooq, Ignition studies of two low-octane gasolines, Combust. Flame 185 (2017) 152-159.

[79] J. Shao, Y. Zhu, S. Wang, D.F. Davidson, R.K. Hanson, A shock tube study of jet fuel pyrolysis and ignition at elevated pressures and temperatures, Fuel 226 (2018) 338-344.

[80] H. Wang, M.A. Oehlschlaeger, Autoignition studies of conventional and Fischer-Tropsch jet fuels, Fuel 98 (2012) 249-258.

[81] Y. Li, A. Alfazazi, B. Mohan, E. Alexandros Tingas, J. Badra, H.G. Im, S. Mani Sarathy, Development of a reduced four-component (toluene/n-heptane/iso-octane/ethanol) gasoline surrogate model, Fuel 247 (2019) 164-178.

[82] H. Wang, E. Dames, B. Sirjean, D.A. Sheen, R. Tango, A. Violi, J.Y.W. Lai, F.N. Egolfopoulos, D.F. Davidson, R.K. Hanson, C.T. Bowman, C.K. Law, W. Tsang, N.P. Cernansky, D.L. Miller, R.P. Lindstedt, A high-temperature chemical kinetic model of n-alkane (up to n-dodecane), cyclohexane, and methyl-, ethyl-, n-propyl and n-butyl-cyclohexane oxidation at high temperatures, http://web.stanford.edu/group/haiwanglab/JetSurF/JetSurF2.0/index.html, (2010).

[83] J. Luche, M. Reuillon, J.C. Boettner, M. Cathonnet, Reduction of large detailed kinetic mechanisms: Application to kerosene/air combustion, Combust. Sci. Technol. 176 (2004) 1935-1963.

[84] J. Bugler, K.P. Somers, E.J. Silke, H.J. Curran, Revisiting the Kinetics and Thermodynamics of the Low-Temperature Oxidation Pathways of Alkanes: A Case Study of the Three Pentane Isomers, J. Phys. Chem. A 119 (2015) 7510-7527.

[85] K.K. Yalamanchi, V.C.O. van Oudenhoven, F. Tutino, M. Monge-Palacios, A. Alshehri, X. Gao, S.M. Sarathy, 
Machine learning to predict standard enthalpy of formation of hydrocarbons, J. Phys. Chem. A 123 (2019) 8305-8313. 